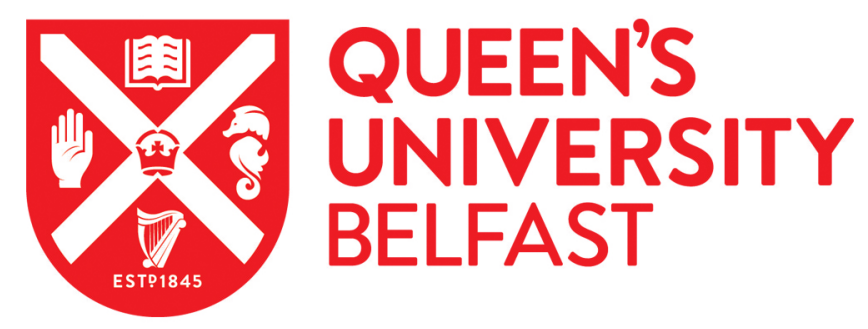

\title{
Slip Sliding Away: Enigma of Large Sandy Blocks within a Gas Bearing Mass Transport Deposit, Offshore NW Greenland
}

Cox, D., Huuse, M., Newton, A., Gannon, P., \& Clayburn, J. (2020). Slip Sliding Away: Enigma of Large Sandy Blocks within a Gas Bearing Mass Transport Deposit, Offshore NW Greenland. Bulletin of the American Association of Petroleum Geologists, 104(5), 1011-1043. https://doi.org/10.1306/10031919011

Published in:

Bulletin of the American Association of Petroleum Geologists

Document Version:

Publisher's PDF, also known as Version of record

Queen's University Belfast - Research Portal:

Link to publication record in Queen's University Belfast Research Portal

Publisher rights

(c) 2020 The American Association of Petroleum Geologists. This is an open access article published under a Creative Commons Attribution License (https://creativecommons.org/licenses/by/4.0/), which permits unrestricted use, distribution and reproduction in any medium, provided the author and source are cited.

\section{General rights}

Copyright for the publications made accessible via the Queen's University Belfast Research Portal is retained by the author(s) and / or other copyright owners and it is a condition of accessing these publications that users recognise and abide by the legal requirements associated with these rights.

Take down policy

The Research Portal is Queen's institutional repository that provides access to Queen's research output. Every effort has been made to ensure that content in the Research Portal does not infringe any person's rights, or applicable UK laws. If you discover content in the Research Portal that you believe breaches copyright or violates any law, please contact openaccess@qub.ac.uk. 


\section{Slip sliding away: Enigma of large sandy blocks within a gas-bearing mass transport deposit, offshore northwestern Greenland}

\section{David R. Cox, Mads Huuse, Andrew M. W. Newton, Paul Gannon, and John Clayburn}

\section{ABSTRACT}

The northwestern Greenland margin contains several underexplored sedimentary basins formed by Cretaceous rifting and Cenozoic postrift sedimentation. The basins are thought to contain significant hydrocarbon reserves, although no exploration wells have been drilled to date. This paper reports the discovery of a gas-charged submarine landslide mass transport deposit (MTD) covering $420 \mathrm{~km}^{2}\left(162 \mathrm{mi}^{2}\right)$ above the Melville Bay ridge (MBR) rift structure. The sedimentary succession that deformed into the MTD was likely deposited within a shallow-marine spit complex developed along the ridge axis extension during the Eocene. The MTD displays landslide characteristics with distinct blocks

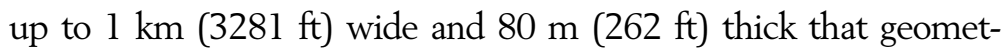
rically fit together like a jigsaw puzzle. Clear direct hydrocarbon indicators and velocity estimations suggest the mass transport blocks are composed of highly porous, gas-charged sands intercalated with shale layers and overlain by postslide pelagic mudstones. The reconstruction of all 499 MTD blocks suggests emplacement by bidirectional sliding, triggered by rejuvenation and a southward tilt of the MBR. Sliding most likely occurred slowly along a low-angle decollement surface, with the blocks remaining intact despite not being confined within a typical slide mass. Instead, coherency was likely aided by lithological layering and diagenesis. Gravitational shedding of the steep block margins has created interblock sand accumulations, which may enhance connectivity.

This study provides an important analog for significant reservoir occurrence in large MTD blocks and provides constraints on the basin development and petroleum prospectivity of northeast Baffin Bay.

Copyright (C2020. The American Association of Petroleum Geologists. All rights reserved. Gold Open Access. This paper is published under the terms of the CC-BY license.

Manuscript received January 11, 2019; provisional acceptance March 21, 2019; revised manuscript received May 23, 2019; final acceptance October 3, 2019.

DOI:10.1306/10031919011

\section{AUTHORS}

DAvid R. Cox Department of Earth and Environmental Sciences, The University of Manchester, Manchester, United Kingdom; david.cox@manchester.ac.uk

David R. Cox joined The University of Manchester in 2016 as a Ph.D. student after working for 2 years in the oil industry. His Ph.D. research is focused on the impacts of glaciation on Arctic petroleum systems, encompassing topics such as seismic geomorphology, fluid flow, gas hydrates, reservoir characterization, basin modeling, and shallow hazard analysis.

MADS HUUSE Department of Earth and Environmental Sciences, The University of Manchester, Manchester, United Kingdom; mads.huuse@manchester.ac.uk

Mads Huuse is professor of geophysics at The University of Manchester. He received his Ph.D. from Aarhus University in 1999 and joined Manchester in 2009 to lead the seismic interpretation group. His interests include basin fill, temperature, diagenesis, gas hydrates, reservoir and seal characterization, and fluid flow. His interests also include seismic geomorphology of glaciated basins and margins.

ANDREW M. W. NEWTON Department of Earth and Environmental Sciences, The University of Manchester, Manchester, United Kingdom; A.Newton@qub.ac.uk

Andrew M. W. Newton received his Ph.D. in seismic geomorphology of glaciated margins from The University of Manchester in 2017. After a short postdoctoral, he joined Queen's University Belfast as an independent research fellow and remains a visiting researcher at Manchester. His current research interests include using seismic geomorphology to understand subsurface evolution, paleoclimate, and fluid flow.

Paul Gannon Cairn Energy, PLC, Edinburgh, United Kingdom; Paul.Gannon@ cairnenergy.com

Paul Gannon is a geoscientist working for Cairn Energy, PLC, as part of the Norwegian North Sea exploration team, based in Stavanger Norway, and previously as part of the North 
Atlantic exploration team, focused on Cairn's Greenlandic portfolio of assets. Paul holds a degree in geology from Trinity College Dublin and a master's degree in petroleum geoscience from Aberdeen University.

JoHn CLAYBURn Cairn Energy, PLC, Edinburgh, United Kingdom; japclayburn@ gmail.com

John Clayburn graduated from the University of Oxford in 1981 with a D.Phil. in radiogenic isotope geochemistry and has published in numerous journals including The Royal Society and Nature. He has more than 35 years of oil industry experience, having looked at rocks in more than 100 countries. His most recent role was head of exploration for Cairn Oil \& Gas, Ltd., and Cairn Energy, PLC.

\section{ACKNOWLEDGMENTS}

The authors would like to thank Cairn Energy, PLC, for access to seismic data from the Pitu area and for permission to publish images and results herein. The results and opinions expressed within this work are those of the authors and are not a representation of Cairn Energy, PLC. We would also like to thank TCS for the provision of the Baffin Bay two-dimensional regional seismic survey (BBRE11).

David R. Cox is part of the Natural Environment Research Council (NERC) Centre for Doctoral Training in Oil \& Gas (grant number: NE/M00578X/1). It is sponsored by The University of Manchester $(50 \%)$ and the British Geological Survey via the British University Funding Initiative (50\%) (studentship number: S356), both of which are gratefully acknowledged. Andrew M. W. Newton was sponsored by Cairn Energy, PLC, and NERC (NE/K500859/1).

Finally, we are grateful for software provisions to The University of Manchester that were used within this work from Schlumberger (Petrel), Esri (ArcMap), and Foster Findlay Associates, Ltd. (Geoteric).

\section{INTRODUCTION}

Sediments deposited by gravitational and mass-wasting processes are commonplace in deep-water settings (Prior et al., 1984; Hampton et al., 1996; Butler and Turner, 2010). These processes can create seismic-scale deposits consisting of chaotic facies that can commonly host rotated and translated slide blocks within the matrix of the flow. These blocks commonly consist of meter- to kilometer-scale packages of undeformed strata that have remained coherent and intact throughout the sliding process (Huvenne et al., 2002; Weimer and Shipp, 2004; Jackson, 2011; Alves, 2015). In the rock record, these deposits are referred to as mass transport complexes or mass transport deposits (MTDs) (Weimer and Shipp, 2004).

On the northwestern Greenland shelf, a well-preserved MTD covering $420 \mathrm{~km}^{2}$ (162 $\mathrm{mi}^{2}$ ) above the Melville Bay ridge (MBR) rift structure has been interpreted using threedimensional (3-D) seismic data. The main objectives of this paper are to document the occurrence, architecture, and lithology of enigmatic, jigsawlike blocks within this potentially gas-charged MTD, while also unraveling the complex depositional and deformational history that led to its emplacement. The paper concludes by assessing reservoir connectivity and the potential for exploration and development.

The discovery of this MTD reservoir was achieved because of renewed exploration interest in the Arctic caused in part by increasing oil prices from 2002 to 2008 and a prediction that the Arctic contains some 30\% and 13\% of the world's undiscovered gas and oil, respectively (Gautier et al., 2009). A significant proportion of this interest was focused offshore West Greenland because of its favorable fiscal terms and unexplored, thick sedimentary rift sequences (Henriksen et al., 2009). This interest prompted hydrocarbon exploration license rounds from 2007 to 2008 and 2010, when five licenses were awarded in northeast Baffin Bay alone (Figure 1). This led to the acquisition of extensive two-dimensional (2-D) seismic data sets that cover much of the wider Baffin Bay area, offshore northwestern Greenland.

Pitu, one of the five awarded blocks within Melville Bay, contains a 3-D seismic survey covering an area of $1672 \mathrm{~km}^{2}$ (646 $\mathrm{mi}^{2}$ ) over part of the MBR and the western flank of the Melville Bay graben (MBG) (Figure 1). The nearest well calibration is more than $300 \mathrm{~km}(>186.5 \mathrm{mi})$ to the south and is used to provide a chronostratigraphic framework for the shallow stratigraphy where key horizons can be tied southward above large areas of volcanic deposits to Ocean Drilling Program (ODP) site 645 (Figure 1) (Knutz et al., 2015; Gregersen et al., 2016). Approximate constraints on the likely ages of 


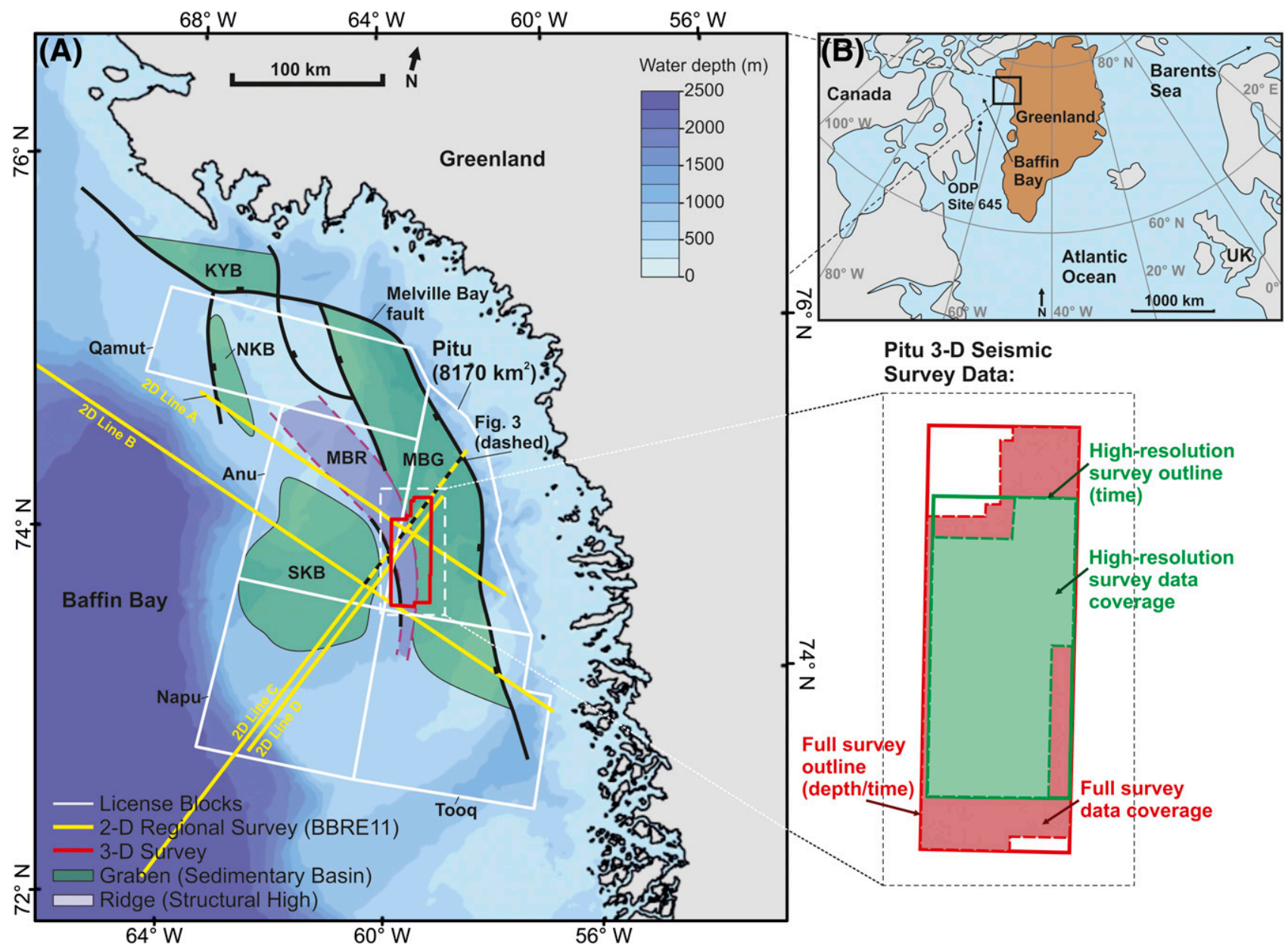

Figure 1. Study area and data location. (A) Bathymetry of the Melville Bay area from Jakobsson et al., (2012) annotated with exploration license blocks, major faults, sedimentary basins, and structural ridges. Two-dimensional (2-D) and three-dimensional (3-D) seismic reflection data coverage is also shown within the map and on the adjacent enlargement. The 2-D line $C$ represents the location of Figure 3. (B) A cartoon map of the Arctic region surrounding Greenland, showing the location of map A and Ocean Drilling Program (ODP) site 645. BBRE11 = Baffin Bay 2-D regional seismic survey; KYB = Kap York Basin; $\mathrm{MBG}=$ Melville Bay graben; MBR = Melville Bay ridge; NKB = North Kivioq Basin; SKB = South Kivioq Basin; UK = United Kingdom.

older stratigraphy are inferred from their stratigraphic relationship to tied mega-unit boundaries, an understanding of the regional geology (Gregersen et al., 2013) and data from seabed sampling (Gregersen et al., 2016) (which was not available for use in this study).

\section{GEOLOGICAL AND TECTONIC SETTING}

The initial onset of rifting between Greenland and Canada began in the Late Jurassic, evidenced by volcanism and intruded dykes to the south of the Pitu (Umpleby, 1979; Larsen et al., 2009).
This was triggered by northward propagation of North Atlantic spreading into the Arctic basins, leading to the creation of oceanic crust in central Baffin Bay during the Paleocene and Eocene (Oakey and Chalmers, 2012; Gregersen et al., 2013). Rifting was focused during the Cretaceous and created a series of northwest-southeasttrending sedimentary basins, separated by elongate structural ridgelike highs (Whittaker et al., 1997) (Figures 1, 2).

These basins and extensive ridges dominated the topography of the Melville Bay area throughout the Paleogene and into the Neogene. The largest of these basins is the 35-90-km (22-56-mi)-wide MBG that 
(A)
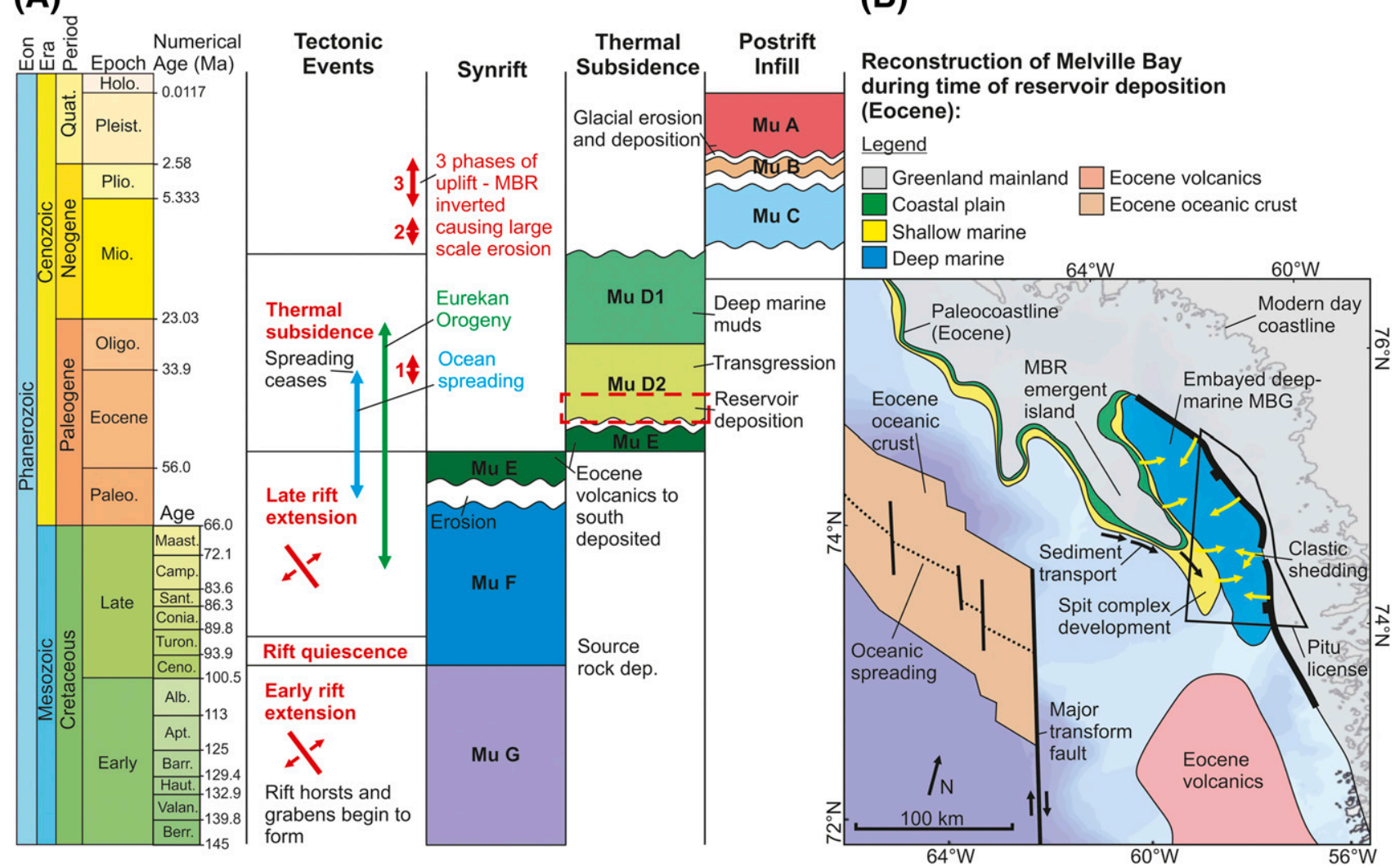

Figure 2. Tectono-stratigraphic development of the Melville Bay region (MBR). (A) Stratigraphic age and the associated rift stages for the interpreted mega-units (Mu) G-A within the Pitu license block. The chart also shows predicted periods of erosion, rifting, and tectonic events associated with basin formation and adjustments as well as the timing of reservoir deposition (dep.) (compiled from Whittaker et al., 1997; Japsen et al., 2006; Oakey and Chalmers, 2012; Gregersen et al., 2013; and Knutz et al., 2015). (B) A reconstruction of Melville Bay during the time of reservoir deposition showing the embayment of the Melville Bay graben (MBG) via the MBR emergent island as well as sediment transport and deposition and the location of sea-floor spreading. Oceanic crust and spreading locations have been modified from Welford et al. (2018). Alb. = Albian; Apt. = Aptian; Barr. = Barremian; Berr. = Berriasian; Camp. = Campanian; Ceno. = Cenomanian; Conia. $=$ Coniacian; Haut. $=$ Hauterivian; Holo. $=$ Holocene; Maast. $=$ Maastrichtian; Mio. $=$ Miocene; Oligo. $=$ Oligocene; Paleo. $=$ Paleocene; Pleist. $=$ Pleistocene; Plio. $=$ Pliocene; Quat. $=$ Quaternary; Sant. $=$ Santonian; Turon.$=$ Turonian; Valan. $=$ Valanginian.

is bounded to the east by the Melville Bay Fault (which shows a maximum heave of $>30 \mathrm{~km}[>18.6$ mi]) and is separated from the Kap York Basin to the north and the Kivioq Basin to the west by the MBR (Whittaker et al., 1997) (Figure 1). The MBR developed as an elongated synrift tilted fault block that has subsequently experienced postrift reactivation (Gregersen et al., 2013) (Figure 1). This ridge likely existed as a small emergent island extending from the Greenland mainland to the north during much of the Paleogene and Neogene (Figure 2). This would have partially separated the deeper waters of the MBG from the rest of Baffin Bay to the west, creating an embayment (Gregersen et al., 2013, 2016).

The restricted basin was infilled by CretaceousPaleogene sedimentary successions that contain mainly marine mudstones with interfingering coarse sands sourced from both the Greenland craton to the east and the uplifted MBR to the west (Gregersen et al., 2013). These successions can reach thicknesses up to approximately $13 \mathrm{~km}$ $(\sim 8 \mathrm{mi})$ and include likely source-rock deposition during the Late Cretaceous (Cenomanian-Turonian) (Whittaker et al., 1997; Bojesen-Koefoed et al., 1999; Planke et al., 2009; Gregersen et al., 2013) (Figure 2). Accommodation upon the MBR was preserved during periods of uplift quiescence, allowing sediments to accumulate and create a thick ( $<80 \mathrm{~m}[<262 \mathrm{ft}])$ package of prograding sands, which constitute the potential reservoir studied here (Oakey and Chalmers, 2012; Gregersen et al., 2013, 2016). 
Major extension and sea-floor spreading ceased during the late Eocene-Oligocene (Oakey and Chalmers, 2012; Welford et al., 2018), with thermal subsidence driving the drowning of the emerged MBR and causing the transgression of clastic systems within Melville Bay as well as a widespread transition into a deep-marine environment (Figure 2) (Whittaker et al., 1997; Gregersen et al., 2013). The margin subsequently underwent several episodes of uplift and exhumation (up to $2 \mathrm{~km}$ [1.2 mi] over three time phases: 36-30 Ma, 11-10 Ma, and 7-2 Ma), evidenced by apatite fission-track modeling, vitrinite reflectance analysis, and seismic studies (Oakey, 2005; Japsen et al., 2006; Knutz et al., 2015) (Figure 2). This led to the creation of significant inversion structures as well as the reactivation of several structural ridges within eastern Baffin Bay, including the MBR (Gregersen et al., 2013). The remnant rift topography of the MBR, along with continued phases of uplift during the late Paleogene and Neogene has caused sediment packages to thin over the high and for the deposition to be concentrated within the deeper basin, leading to the wedgelike geometry of postrift packages (Figure 3) (Whittaker et al., 1997; Japsen et al., 2006; Gregersen et al., 2013, 2016). This effect is increased by sand input from the Greenland craton to the east, depositing within the deeper basin before reaching the MBR slope (Knutz et al., 2012, 2015; Gregersen et al., 2013, 2016).

The late Pliocene and Pleistocene cycles of glacial advance and retreat of the Greenland Ice Sheet have caused the adjacent northwestern Greenland continental shelf to be extensively reworked (Aksu and Piper, 1987). This is evidenced by several erosional surfaces and several significant glacial sedimentary wedges overlying much of the deeper rift sequence within Baffin Bay (Knutz et al., 2015, 2019; Newton et al., 2017) (Figure 3).

The differentiation between basin and ridge rift structures and the thick sedimentary succession within the MBG is clearly evident on seismic data across the Pitu license block (Figure 3). The 2-D and 3-D seismic data used within this study have been interpreted, resulting in nine seismic stratigraphic (mega-unit) horizons that define the sedimentary infill of the basin (Figures 2, 3). These regional interpretations follow the work completed by Gregersen et al. (2013, 2016, 2019). This work defines the main rift-related sediments within the MBG as mega-units G-D1, which are overlain by postrift infill as well as glaciogenic sediments (mega-units $\mathrm{C}-\mathrm{A}$ ). The reservoir that this study focuses on exists within the base of mega-unit D2 (Figures 2, 3). These sediments are underlain by early rift sediments that thin onto the high and are overlaid by polygonally faulted infill muds of mega-unit Dl (Figure 3).

\section{DATA AND METHODS}

The main data set used within this study consisted of a 3-D seismic reflection survey that was acquired by Cairn Energy, PLC, in 2011 that consists of 93 3-D acquisition lines using a bin size of $25 \times 12.5 \mathrm{~m}(82 \times$ $41 \mathrm{ft})$ and $1-\mathrm{km}(0.62-\mathrm{mi})$ separation between sail lines (Figure 1). The shotpoint interval used was 25 $\mathrm{m}$ (82 ft) (flip-flop) with a source separation of $50 \mathrm{~m}$ $(164 \mathrm{ft})$, leading to a common midpoint fold of $70 \mathrm{~m}$ (230 ft). The total survey area is $1672 \mathrm{~km}^{2}\left(646 \mathrm{mi}^{2}\right)$ with $12.6 \%$ data infill and is provided in two-way time (TWT) down to $6.5 \mathrm{~s}$. Processing steps included signal noise attenuation and corrections and velocity analysis using Kirchhoff prestack time migration (PSTM). The frequency ranges between 5 and 75 $\mathrm{Hz}$, with a dominant frequency within the target interval of $28 \mathrm{~Hz}$ producing a dominant wavelength of $71 \mathrm{~m} \mathrm{(233} \mathrm{ft)} \mathrm{(using} \mathrm{an} \mathrm{average} \mathrm{velocity} \mathrm{of}$ $2.0 \mathrm{~km} / \mathrm{s}$ [6562 ft/s]) and a vertical resolution of $18 \mathrm{~m}$ $(59 \mathrm{ft})$. Prestack depth migration was completed using a Kirchhoff algorithm down to $10,000 \mathrm{~m}(32,808 \mathrm{ft})$.

The survey was reprocessed in 2013, which included a more detailed poststack depth migration study using a Kirchhoff algorithm and attempted to remove several unwanted features such as a residual bubble oscillation, strong seabed multiples, and wave diffractions caused by glacial seabed scours. A subset high-resolution 3-D seismic survey in TWT was also produced that covers an area of $1135.5 \mathrm{~km}^{2}$ (438 $\left.\mathrm{mi}^{2}\right)$ down to $5 \mathrm{~s}$, with a frequency range of $5-150 \mathrm{~Hz}$ and a dominant frequency across the target interval of $45 \mathrm{~Hz}$ producing a dominant wavelength of $44 \mathrm{~m}$ (144 ft) (using an average velocity of $2.0 \mathrm{~km} / \mathrm{s}[6562 \mathrm{ft} / \mathrm{s}])$ and an increased vertical res-

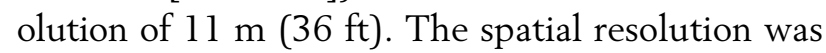
also increased to $12.5 \mathrm{~m}$ (inline) $\times 6.25 \mathrm{~m}$ (crossline) $(41 \times 20.5 \mathrm{ft})$ (Figure 1$)$.

The data used in this study also include four regional 2-D seismic reflection lines (Figure 1) that 

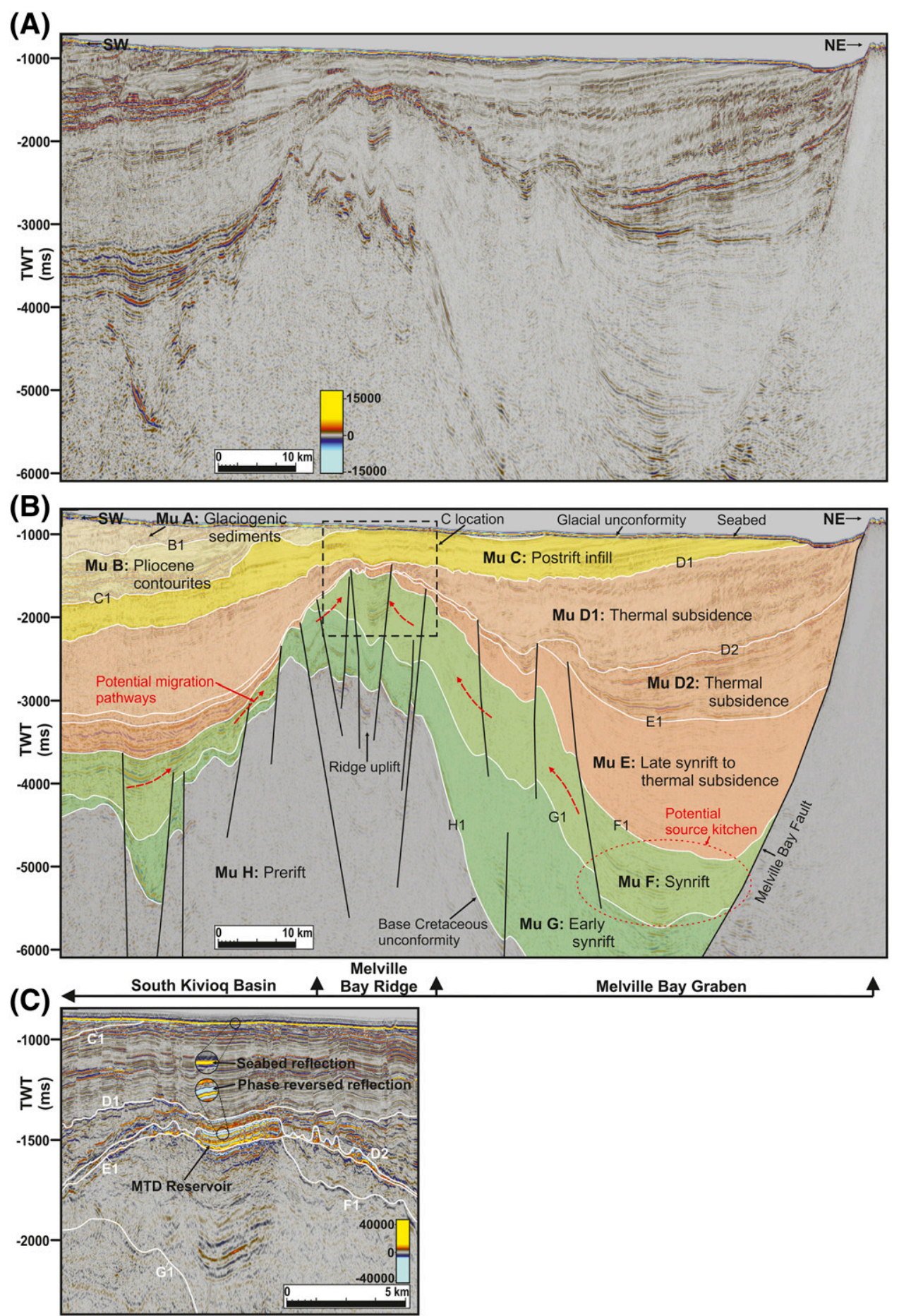

Figure 3. Regional basin development and structure. (A) An uninterpreted regional two-dimensional (2-D) seismic reflection line (2-D line A) showing the basin and ridge structure across the study area. (B) An interpreted regional 2-D seismic reflection line (2-D line A) showing nine mega-unit $(\mathrm{Mu})$ horizons that have been modified from Gregersen et al. $(2013,2016,2019)$ as well as rift stage interpretations. Also shown are interpretations of possible source-rock kitchens and updip migration pathways within the Cretaceous Mu $\mathrm{F}$. (C) A seismic reflection intersection from the high-resolution three-dimensional survey along the 2-D line trajectory (location shown in (B)) to show the location of the main mass transport deposit (MTD) reservoir studied as well as the polarity comparison of the top reservoir and seabed. The 2-D seismic line location is shown in Figure 1. TWT = two-way time. 
form part of the Baffin Bay 2-D regional seismic survey data set (BBRE11), provided by TGS, that was acquired between 2007 and 2009, covering $5226.5 \mathrm{~km}$ (3248 mi) across Melville Bay. This survey was acquired using a 2000 psi source with a $25-\mathrm{m}$ (82-ft) interval and $8-\mathrm{m}(26-\mathrm{ft})$ gun depth. Data were recorded by a single 6000-m (19,685-ft) streamer with 480 channels spaced at $12.5-\mathrm{m}(41-\mathrm{ft})$ intervals, using a sample interval of $2 \mathrm{~ms}$. The survey was reprocessed in 2011, which involved bubble-pulse attenuation, diffraction multiple attenuation, lowfrequency enhancement, and Kirchhoff PSTM.

All seismic data were provided in Society of Exploration Geophysicists normal polarity, with positive peaks (red) representing a downward increase in acoustic impedance and negative troughs (blue) representing a downward decrease in acoustic impedance (Figure 3C).

Converting the TWT thickness of blocks interpreted within the high-resolution seismic survey to depth was completed using an estimated average interval velocity of $1.69 \mathrm{~km} / \mathrm{s}(5545 \mathrm{ft} / \mathrm{s})$, which was calculated from the velocity pushdown effect observed beneath the reservoir blocks in seismic data (see the Seismic Observations section). This method was used instead of directly measuring the thicknesses on the depth-converted seismic survey. This was because of the increased vertical resolution within the high-resolution survey allowing more accurate imaging and interpretation of the blocks, leading to a more accurate thickness estimate. Seismic observations and interpretations were made within Schlumberger's Petrel software using industry-standard seismic interpretation techniques (Posamentier, 2004; Posamentier et al., 2007). Spectral decomposition was completed and interpreted using Geoteric, which allowed for noise cancellation, seismic frequency selection, and color blend cube creation (Castagna and Sun, 2006). Surface extractions were then taken from color blend cubes for interpretation (Wright et al., 2018).

The landslide reconstruction process was carried out in ArcMap, in which the blocks were iteratively returned to their likely source location by comparing the following.

1. Geometrical fit: Because of block coherency, the shape and structure of the reservoir blocks in map view remains visible and allows for a geometrical reconstruction, much like jigsaw pieces, in which the pieces are slid back together. This process considered mass wasting and erosion at the block edges, giving a slightly blurry fit, and block translation and rotation.

2. Block thickness: Blocks that were once connected laterally adjacent to each other would likely be of similar thickness. Thickness trends across multiple blocks were used to constrain the reconstruction.

3. Internal reflections: Matching internal reflections from seismic profiles showed continuous depositional style and constituents across originally adjacent blocks.

4. Dip and azimuth of decollement surface: Because the uplift of the MBR is the most likely trigger of slide movement, the decollement surface structure was used as a guide to the possible flow paths and the direction of sliding along which the blocks can be repositioned in their original location.

The process only considered reservoir blocks that were thicker than $30 \mathrm{~ms}(\sim 25 \mathrm{~m}[\sim 82 \mathrm{ft}])$ in thickness. This allowed for a clear definition between reservoir blocks and interblock areas and defined a total of 499 individual blocks for use in the reconstruction. The assumption was made that the large main reservoir block existing on the MBR platform remains in its original location of deposition, allowing for the remaining blocks to be reconstructed back to this center. The preslide location for each of the reservoir blocks was decided using the four guiding characteristics of either the blocks themselves or the underlying decollement surface outlined above. If the four considerations matched, then the blocks were moved into laterally adjacent positions. Each block was restored separately, according to the guiding characteristics, but the final fit of each block depended on the fit of previously reconstructed blocks.

The most likely direction of block sliding (flow line) was determined by comparing the pre- and postslide location and orientation of individual blocks. Additionally, this process considered the pathway for all surrounding blocks, as deformational trends likely occurred across multiple block sections, with the crossing of individual slide paths being unlikely. This allowed an iterative assessment 
of block flow lines working outward from the main reservoir block, creating trends that agreed across multiple blocks as well as connecting individual preand postslide block locations. Direct evidence of flow direction, such as erosional structures on the decollement surface, is not observed. This is possibly either because of a lack of beneath-block erosion occurring during sliding or existing features not being imaged within the seismic data. This may be because of limited vertical seismic resolution or beneath-block velocity pushdown significantly affecting the imaging and structure of the decollement surface.

\section{SEISMIC OBSERVATIONS}

A package of bright amplitudes and potential direct hydrocarbon indicators (DHIs) that exist on the crest and eastern flank of the MBR have been investigated using the Pitu high-resolution 3-D seismic survey. This package exists at the base of mega-unit D2, which consists of Paleogene sediments (Gregersen et al., 2013), with the top D1 horizon having been interpreted as middle Miocene via a long-distance tie to ODP site 645 (Knutz et al., 2012, 2015) (Figure $3)$. The package is likely Eocene in age because of the correlation of the base package horizon (top mega-unit E) into Eocene volcanics to the south of Melville Bay (Gregersen et al., 2013).

\section{Mass Transport Deposit Characteristics}

Seismic interpretation of the uppermost soft reflection revealed that this was associated with an extensive deposit that covers an area of $420 \mathrm{~km}^{2}$ (162 $\mathrm{mi}^{2}$ ) (Figure 4). The strong negative amplitudes are observed across much of the crest and eastern flank of the MBR, with the highest negative amplitudes existing on the platformlike section of the MBR in the north. The response is observed to extend southeast along the strike of the MBR but becomes less continuous to the south and east (Figure 5). Bright amplitudes are, however, observed to the south of 3-D seismic coverage on 2-D regional line B (Figure 1) on the boundary of the Pitu and Tooq license blocks. This may suggest the package extends beyond the southern limit of the 3-D survey.
The discontinuous soft response indicates that the package of reflections has broken up into several angular blocks that become smaller and further spaced apart to the south and east (Figure 4B) before becoming no longer observed further downslope (having likely disintegrated) (Figure 5). The angular blocks range in sizes up to $1 \mathrm{~km}(3281 \mathrm{ft})$ wide and $80 \mathrm{~m}(262 \mathrm{ft}$ ) thick (maximum TWT of $95 \mathrm{~ms}$ at $1.69 \mathrm{~km} / \mathrm{s}$ [1.05 mi/s]), with block thickness increasing toward the northwest (Figure 5). The entire deposit sits on a single decollement surface (Figure 4) that is consistent with the elongated dome structure created by the uplifted MBR. The deposit is observed to still be intact (with a continuous soft reflection) across much of the platformlike section of this decollement above the MBR to the north (Figures $4 \mathrm{~A}, 5)$. However, away from the central axis of the MBR where the decollement dip increases, the blocks show evidence of movement, with dominant sliding directions to the south in the dip direction along strike of the MBR and also to the east toward the deeper graben (Figure 5).

On the western flank of the MBR, some extensive elongate ridgelike blocks have dislodged from the headscarp but have not disintegrated into smaller isolated blocks such as observed on the eastern flank (Figure 5). The high-amplitude response is not observed further down the steeply dipping western slope or on regional 2-D seismic lines that extend beyond the $3-\mathrm{D}$ seismic survey limits to the west.

\section{Direct Hydrocarbon Indicators}

The seismic expression of the blocks shows clear DHIs with bright soft and hard events at the top and base of the package, respectively, with internal architectures that range from multiple continuous layers of varying acoustic impedance to more homogenous blocks with dim discontinuous internal reflections (Figure 4). The deposit appears to have slid along a single decollement surface that displays as a positive amplitude response with reflection amplitudes increasing beneath the blocks. The approximately plane-parallel decollement surface also shows variable TWT between areas beneath and adjacent to the blocks. This is most likely caused by 

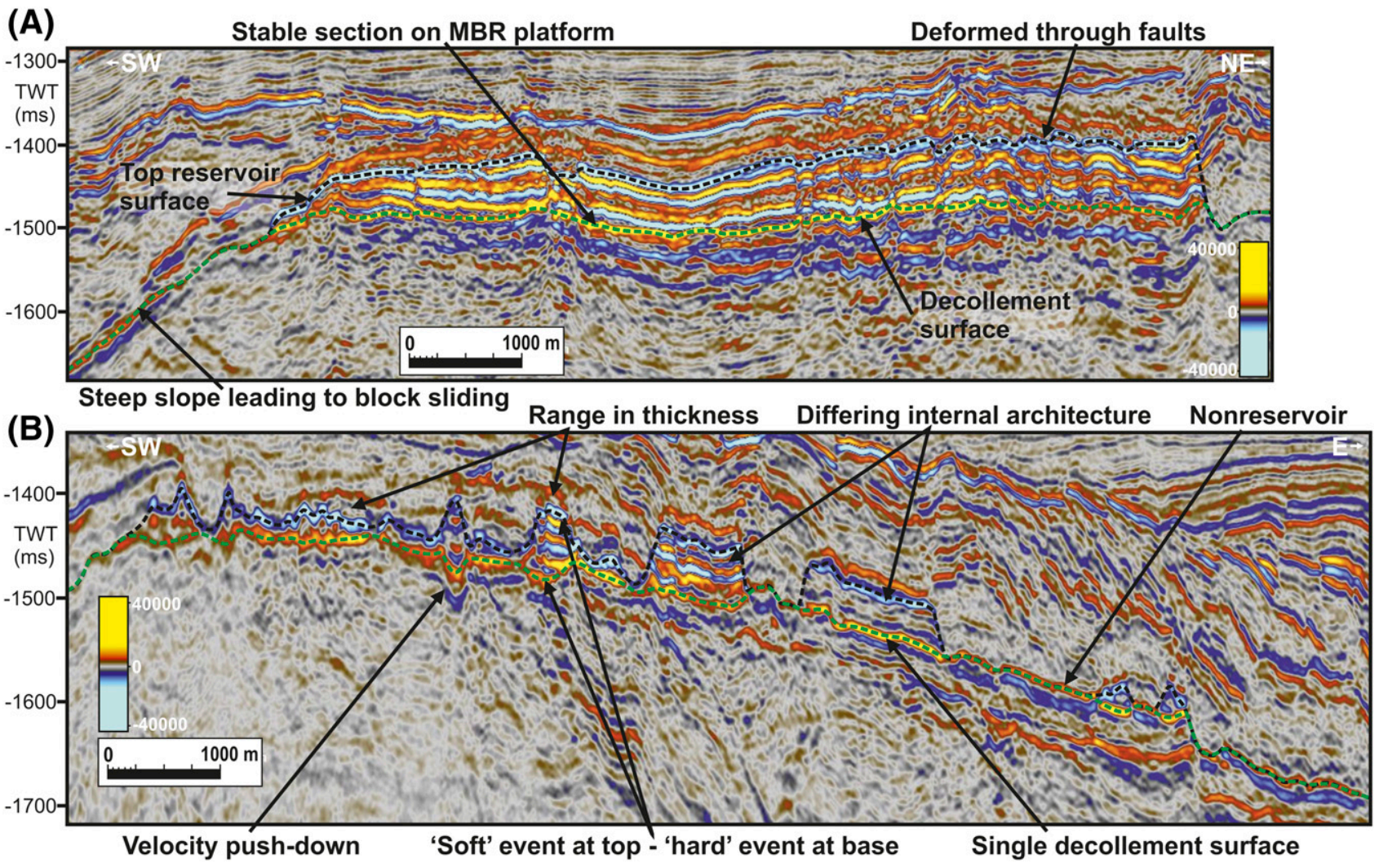

Figure 4. Reservoir description. (A) Seismic section showing the seismic response from the reservoir on top of the Melville Bay ridge (MBR) platform. (B) Seismic section showing the seismic response of distributed reservoir blocks along the eastern ridge slope decollement surface. Line locations are shown in Figure 5. TWT = two-way time.

velocity pushdown because of anomalous fluids such as gas or oil within the package (Figure 4).

The velocity pushdown effect observed beneath the blocks has been used to estimate the primary wave velocity within the package in an attempt to understand its potential lithology and fluid content and to specifically test whether the DHIs observed could be caused by porous, gas-bearing sands. This estimation uses the difference in TWT depth of the decollement surface in areas beneath and adjacent to the blocks (in areas in which the DHI response is not observed) (Figure 6). In reality, the decollement surface is continuous in depth between the two areas, but slower velocities within the package are causing the apparent shift and are likely created by either a different lithology or pore fluid compared to the surrounding overburden (Figure 6B, C). The extent of the velocity reduction will provide evidence to what lithology and pore fluid the package may consist of.

A typical reservoir block was selected for this calculation and is shown in Figure 6. The TWT value from the top of the package to the decollement surface adjacent to the block (without the pushdown) ( $\left.T W T_{\text {norm }}\right)$ is used to calculate the block height $(H)$ (equation 1 ). This assumes an average velocity for the overburden sediments $\left(V_{\text {overburden }}\right)$ of $2.0 \mathrm{~km} / \mathrm{s}(6562 \mathrm{ft} / \mathrm{s})$. This gives a block height of $70 \mathrm{~m}(230 \mathrm{ft})$. The average velocity for within the block was then calculated using this block height along with the TWT value for the block and the pushdown $\left(T W T_{\text {slow }}\right)$, measured from the top reflection to the decollement surface beneath the block (equation 2). This gives an estimated average velocity through the block $\left(V_{\text {block }}\right)$ of $1.69 \mathrm{~km} / \mathrm{s}(5545 \mathrm{ft} / \mathrm{s})$, with this value being used for block thickness conversions from the TWT to depth. Additionally, if the overburden velocity is assumed at $2.2 \mathrm{~km} / \mathrm{s}(7218$ $\mathrm{ft} / \mathrm{s}$ ) instead, the block velocity is then estimated at $1.85 \mathrm{~km} / \mathrm{s}(6070 \mathrm{ft} / \mathrm{s})$.

$$
H=\frac{T W T_{\text {norm }}}{2} \times V_{\text {overburden }} 70 \mathrm{~m}=\frac{70}{2} \times 2.0
$$




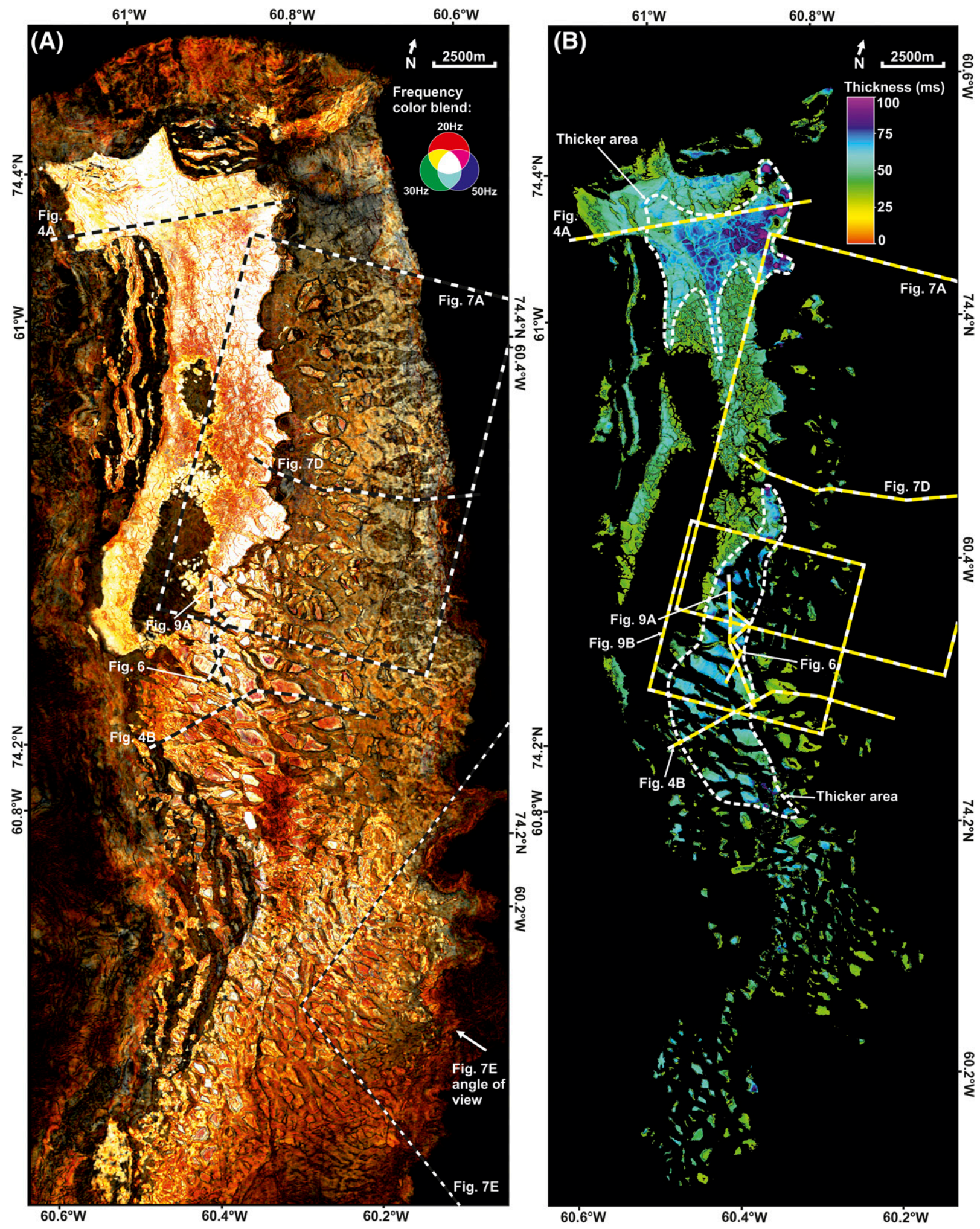

Figure 5. Reservoir distribution and character. (A) Spectral decomposition red, green, and blue (RGB) extraction on the top reservoir surface across the Pitu high-resolution seismic survey. The RGB blend is composed of $20-\mathrm{Hz}$ (red), $30-\mathrm{Hz}$ (green), and $50-\mathrm{Hz}$ (blue) frequency band volumes, created and visualized within Geoteric. (B) A thickness map between the top reservoir and decollement surfaces (filtered to only show thicknesses $>30 \mathrm{~ms}$ ). Two areas of thicker reservoir are highlighted. The locations of Figures 4A, B; 6; 7A, D, E; and $9 A, B$ are shown. 

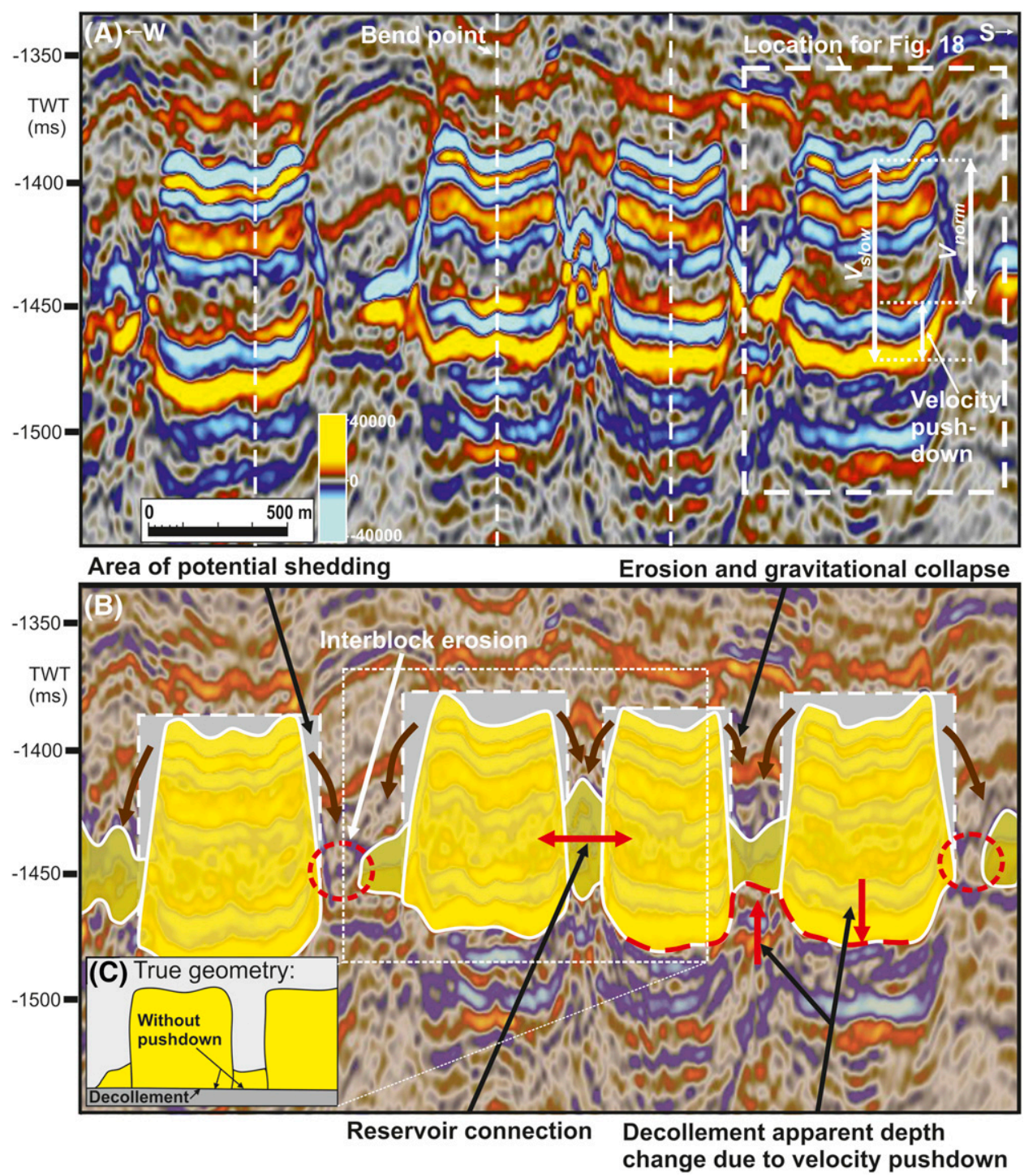

Figure 6. Block erosion and interblock sediment deposition. (A) Uninterpreted seismic section showing four separated reservoir blocks along a single decollement surface. Location of seismic image used within Figure 18 is shown. (B) Interpreted seismic section highlighting reservoir blocks, gravitational shedding, and interblock sediment deposition. The location of the seismic line is shown in Figure 5. TWT = twoway time; $V_{\text {norm }}=$ average velocity adjacent to the block (without pushdown); $V_{\text {slow }}=$ average velocity within the block (with pushdown).

$$
V_{\text {block }}=\frac{H \times 2}{T W T_{\text {slow }}} 1.69 \mathrm{~km} / \mathrm{s}=\frac{70 \times 2}{83}
$$

This estimation, however, only considers the block to consist of $100 \%$ sand, at which point it is far more likely to contain several muddy layers, as evidenced by internal seismic reflections (Figures 4, 6). Considering the amount of internal layers within the typical block, it is estimated that mud could comprise up to one-third of the total block thickness (Figure 6). Therefore, the mud must be considered in the velocity estimation because these low porosity layers will retain the overburden velocity $(2.0 \mathrm{~km} / \mathrm{s}$
[6562 ft/s]) and not create the velocity pushdown observed. The slower velocities causing the pushdown effect will likely be confined to the higher-porosity sand layers within the block.

$$
\begin{aligned}
\text { Sand velocity }\left(V_{\text {sand }}\right) & =\frac{\frac{2}{3} H \times 2}{T W T_{\text {slow }}-\frac{1}{3} T W T_{\text {norm }}} \\
1.56 \mathrm{~km} / \mathrm{s} & =\frac{46.6 \times 2}{83-23.3}
\end{aligned}
$$

The estimation of $V_{\text {sand }}$ (equation 3) only considers the two-thirds of the block height that is sand and 
removes the TWT of the mud layer $\left(0.33 T W T_{\text {norm }}\right)$ from $T W T_{\text {slow }}$. This gives an estimated velocity for the sand layers within the package of $1.56 \mathrm{~km} / \mathrm{s}$ $(5118 \mathrm{ft} / \mathrm{s})$, which is significantly lower than that of typical sandstones with $30 \%-40 \%$ porosity at this depth (commonly 2-2.5 km/s [6562-8202 ft/s]) (Rider and Kennedy, 2011). This velocity reduction is, therefore, most likely caused by the pore fluid within the sands and suggests that the package consists of gas-charged highly porous sands.

A spectral decomposition color blend of 10 (red), 20 (green), and $50 \mathrm{~Hz}$ (blue) (equivalent to a tuning thicknesses of 42, 21, and $8.5 \mathrm{~m}[138,69$, and $28 \mathrm{ft}$ ] at $1.69 \mathrm{~km} / \mathrm{s}$ [5545 ft/s]) was created using the high-resolution 3-D seismic survey. An extraction along the top reservoir horizon clearly depicts a dominant bright white frequency response over much of the reservoir area (Figure 5). This represents high saturations from all three blended frequencies and is a response typical for a relatively shallow (550 $\mathrm{ms}[550 \mathrm{~m}\{1804 \mathrm{ft}\}]$ using an average velocity of 2.0 $\mathrm{km} / \mathrm{s}$ [6562 ft/s]) below the seabed) gas sand reservoir (Wright et al., 2018). Other areas of the reservoir and surrounding decollement surface show dominance toward the low-frequency (red) response. The image also highlights the breakup of the deposit into a large number of separated blocks, with the thickest and most laterally extensive reservoir sections existing on the MBR platform in the north and the increased breakup and movement of smaller blocks mainly to the south and east (Figure 5A). The reservoir is shown to thicken in two areas within the deposit, with reservoir thickness up to $80 \mathrm{~m}$ (262 ft) (Figure 5B).

Spectral decomposition also highlights the same bright, multiple-frequency response seen for the reservoir blocks within certain interblock areas surrounding the large separated blocks south of the main reservoir section (Figure 5A). This signature was also noted in the seismic extraction on the top reservoir surface and in the seismic cross section where interblock areas show similar soft and hard kicks to that of the main reservoir blocks (Figure 6). The seismic sections show that the separated reservoir blocks narrow upward as well as the hummocky and erosive nature of the top reservoir reflections. The cross section shows that the high-amplitude response from the interblock area is absent in places. This can also be observed in Figure 5A in which dark areas between the interblock bright responses represent areas of absence. This absence of response is more prevalent deeper into the graben on the eastern flank and between the smaller blocks within the far southeastern section.

\section{Deformation}

The spectral decomposition image (Figure 5) also highlights a series of east-west elongate and/or oblong features on the top reservoir surface that vary in frequency response and terminate at a similar depth on the slope ( -1600 ms) (Figure 7A) at their western edge. To the east of this termination, no brightamplitude reservoir blocks are observed. Seismic amplitude extractions across these features display a dim, negative amplitude response (Figure 7A). The onset of these features updip commonly occurs at the location of ridge-parallel extensional faults, with the feature existing on the downthrown, slightly steeper part of the slope (Figure 7). Similarly, the features commonly terminate downslope at fault locations. Within each of the features exists numerous linear, low-amplitude zones that are perpendicular to their east-west orientation (Figure 7B). These zones represent the location of small extensional faults (Figure 7B, C). In the east, and downslope of the termination of these features, several deep, valleylike erosional depressions that trend basinward are observed on the decollement surface. High positive (hard kick) seismic amplitude responses are observed to be confined within these depressions that extend downslope and likely beyond the eastern edge of the seismic survey (Figure 7E).

All of the reservoir features observed sit on a single decollement surface (Figure 4). To ascertain controls on the slide block distribution, the presentday dip of the decollement has been estimated (Figure 8). Because subsequent deformation has augmented the paleotopography, the present-day angles are likely much greater than the original decollement dip at the time of slide emplacement. The dip of the decollement increases away from the MBR axis with a flatter, platformlike area on top of the ridge and along strike (Figure 8). The majority of the reservoir blocks exist within the green low dip areas $\left(0^{\circ}-2^{\circ}\right)$, with blocks becoming increasingly broken up into areas of increasing $\operatorname{dip}\left(1^{\circ}-4^{\circ}\right)$ and 


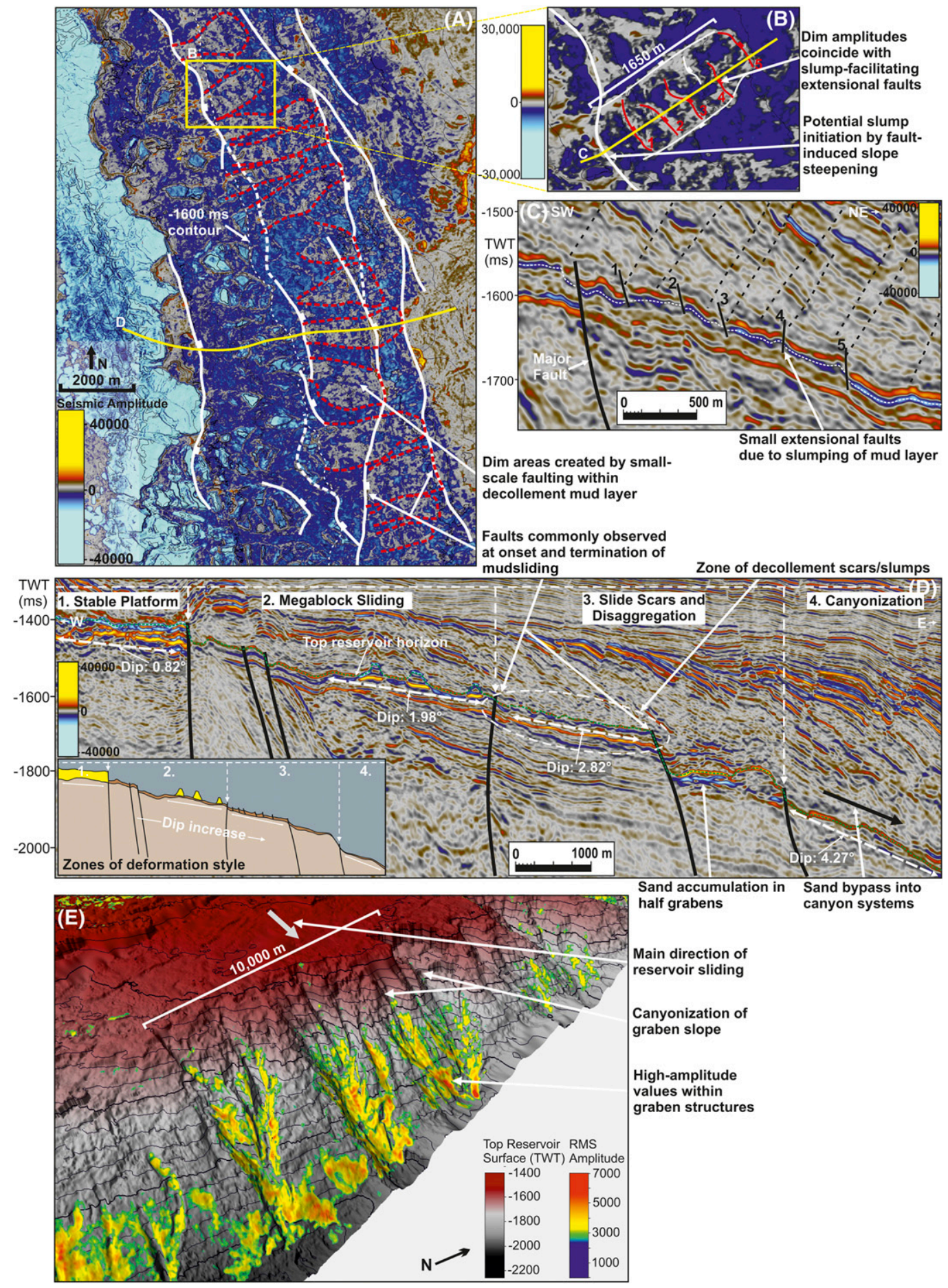

Figure 7. Seismic character transition and zones of deformation style including decollement surface slumping and canyonization. (A) A two-dimensional (2-D) aerial view of a top reservoir seismic extraction surface showing the location of low-amplitude anomalous zones and their relationship to the interpreted fault network. (B) A close-up 2-D aerial view of the top reservoir (decollement because reservoir is not present) extraction surface showing interpreted extensional faults within a low-amplitude feature. (C) A seismic section through the feature shown in (B), showing the location of small extensional faults that allow deformation of the decollement surface. (D) A seismic section showing four zones of deformation style across the reservoir and decollement surface area. The insert shows the four zones in schematic style. (E) A top reservoir two-way time (TWT)-structural surface showing slope canyonization on the eastern flank of the Melville Bay ridge. Topographically controlled shed reservoir sediment is depicted deposited within the canyons as a filtered root-meansquare (RMS) amplitude surface. The locations as seen in (A) and (E) are shown in Figure 5. 

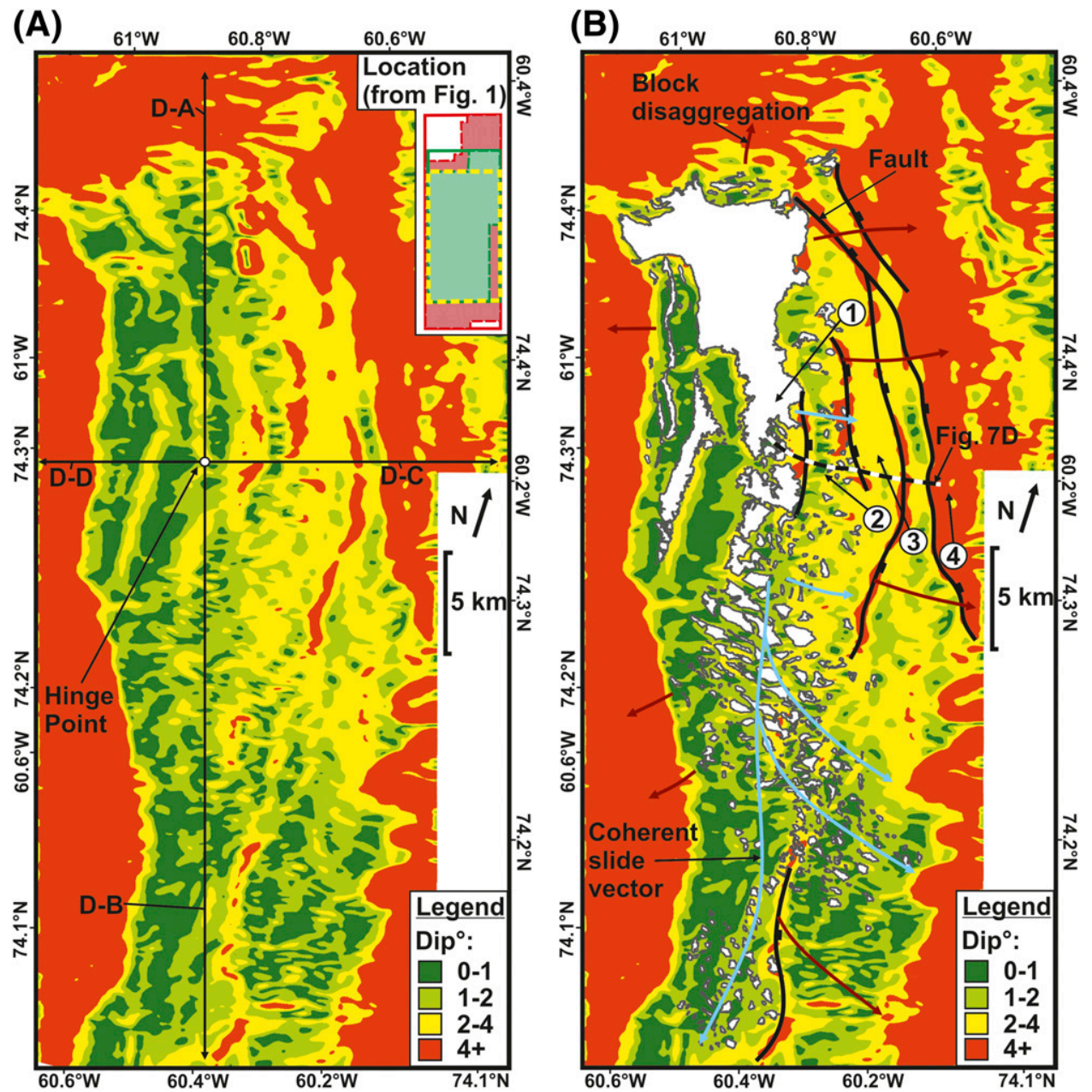

Figure 8. The dip of the decollement surface and its control on block sliding and deformation styles. (A) An uninterpreted dip map of the modern-day reservoir decollement surface (shown in Figure 4) that shows dip increasing away from the relatively flat central axis of the Melville Bay ridge. Four dip transects are shown extending from a central hinge point location on top of the ridge with average dip measurements of $1.6^{\circ}(\mathrm{D}-\mathrm{A}), 0.41^{\circ}(\mathrm{D}-\mathrm{B}), 3.3^{\circ}(\mathrm{D}-\mathrm{C})$, and $2.6^{\circ}$ (D-D). (B) An interpreted dip map of the modern-day reservoir decollement surface, overlaid by the modern-day distribution of reservoir blocks. The increase in dip downslope (eastward) is shown to coincide with a transition of deformational styles, with areas separated by zones of increased dip created by faults. These zones are numbered on the map and defined as (1) stable platform crest, (2) mega-block sliding, (3) slide scars and disaggregation, and (4) canyonization. The control of the dip on sliding is shown by coherent sliding vectors for visible reservoir blocks (blue arrows) remaining within areas of low dip, whereas areas of steeper dip highlight where the reservoir blocks are not visible with the sand likely having disaggregated and shed downslope (shown by sediment shedding vectors [red arrows]).

completely absent in areas of high $\operatorname{dip}\left(\geq 4^{\circ}\right)$ shown in Figure 8 . The variations in reservoir signature across areas of increasing dip are commonly separated by linear areas of high dip $\left(\geq 4^{\circ}\right)$ that represent fault locations (Figures 7D, 8). Blocks are commonly observed adjacent to these features updip but are not observed in the downdip section (Figures 7D, 8).

The dip of the decollement also highlights a hinge point on top of the ridge where spreading occurred radially from this high point. This coincides with the onset of block separation and sliding to the south away from the main reservoir block in the north. The higher-average slope angles shown by transects D-A $\left(1.6^{\circ}\right)$, D-C $\left(3.3^{\circ}\right)$, and D-D $\left(2.6^{\circ}\right)$ (Figure 8A), highlight areas in which the slope angle dramatically increases away from the ridge hinge point, coinciding with shorter sliding vectors and a lack of observed reservoir blocks. Transect D-B, along strike of the MBR, shows the most gradual dip, with an average dip angle of $0.4^{\circ}$. In this direction, the majority of reservoir blocks are still observed intact, having slid further distances downslope (Figure 8). 

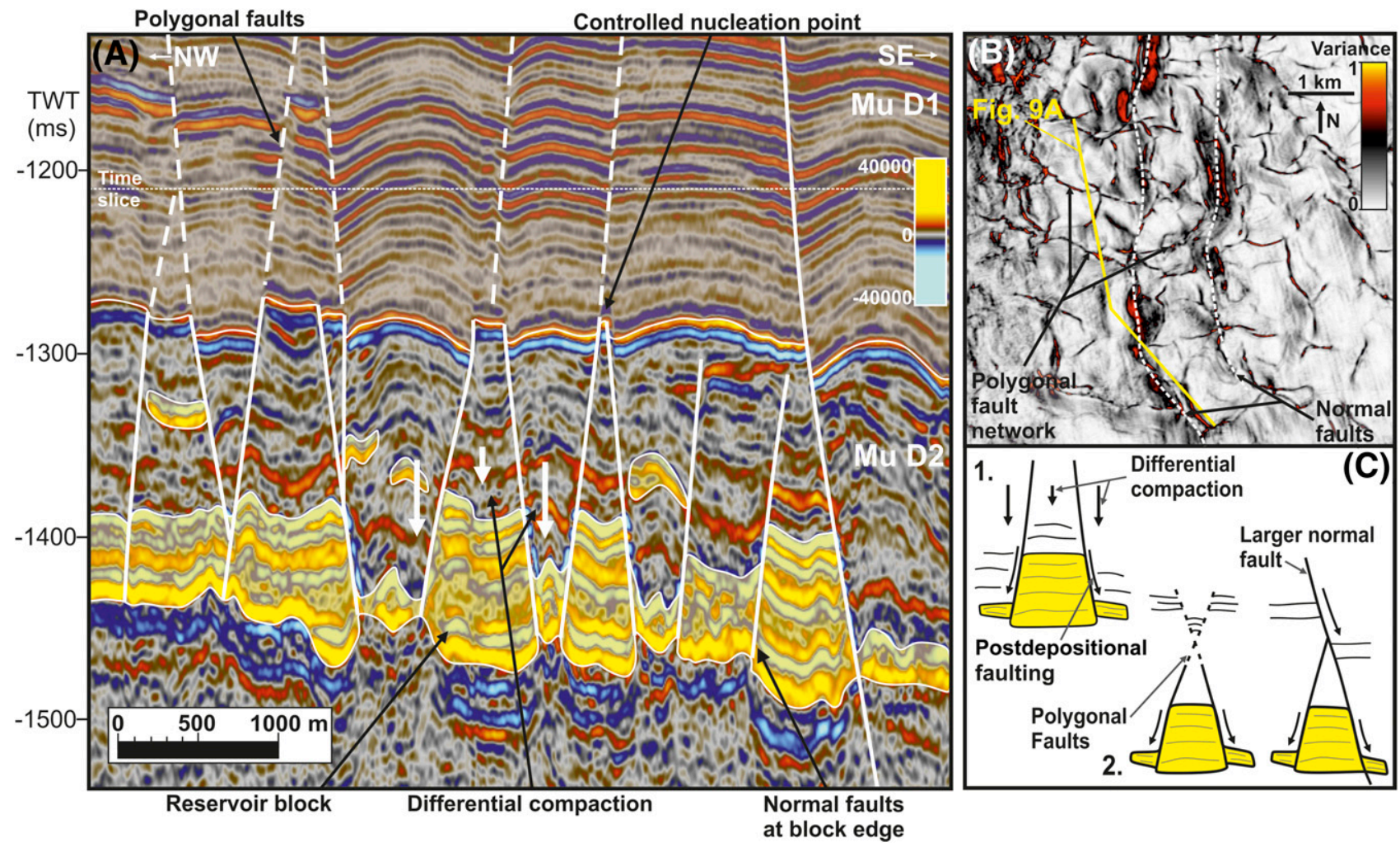

Figure 9. Reservoir block control on the development of a diagenetic polygonal fault network. (A) Interpreted seismic section showing separated reservoir blocks flanked by normal faults that coincide with the nucleation point of polygonal faults within the overlying megaunit (Mu) D1. The location is shown in Figure 5. (B) Variance time slice at $-1210 \mathrm{~ms}$ two-way time (TWT) showing the network of polygonal faults that have formed within Mu D1. The location is shown in Figure 5B. (C) Schematic diagram depicting the influence of reservoir block location on the development of polygonal faults and larger offset normal faults.

\section{Controls on Fault Development}

Reservoir blocks are flanked at their edges by normal faults that extend subvertically through the overburden and into the base of mega-unit Dl (Figure 9A). Mega-unit Dl is characterized by numerous small horst and graben packages of discontinuous horizons that are offset and separated by thin, linear, subvertical low-amplitude zones (Figures 3, 9A). Coherency and variance attribute time slices from within mega-unit D1 (Figure 9B) show how these zones commonly connect to create networks, a typical characteristic of polygonal faults (Cartwright et al., 2003). These faults are mostly layer bound within the deep-water muds of mega-unit Dl but show occasional fault extensions into mega-unit $\mathrm{C}$ and can reach close to the seabed. Many of these polygonal faults are shown to nucleate at the vertical extent of the block, bounding normal faults with the orientation of extension commonly following the directional trend set out by the underlying faults and block-edge orientations (Figure 9A, C). Additionally, a small number of the block-edge normal faults seem to extend directly through mega-units Dl and C and are likely tectonic faults rather than polygonal. These faults show larger degrees of offset with a continuous orientation of extension that is still determined by the location of the block edge.

\section{LANDSLIDE RECONSTRUCTION}

The reconstruction of the 499 landslide blocks to their preslide configuration was facilitated by the high quality of imaging in the high-resolution 3-D survey used and the unique dispersal pattern and angular edges of the reservoir slide blocks. The reconstruction aids the understanding of the triggers and mechanisms of sliding as well as the uplift history of the MBR.

The comparison maps (Figure 10) show the reconstructed location of the blocks that remain within the study area, along with large sections of exposed 

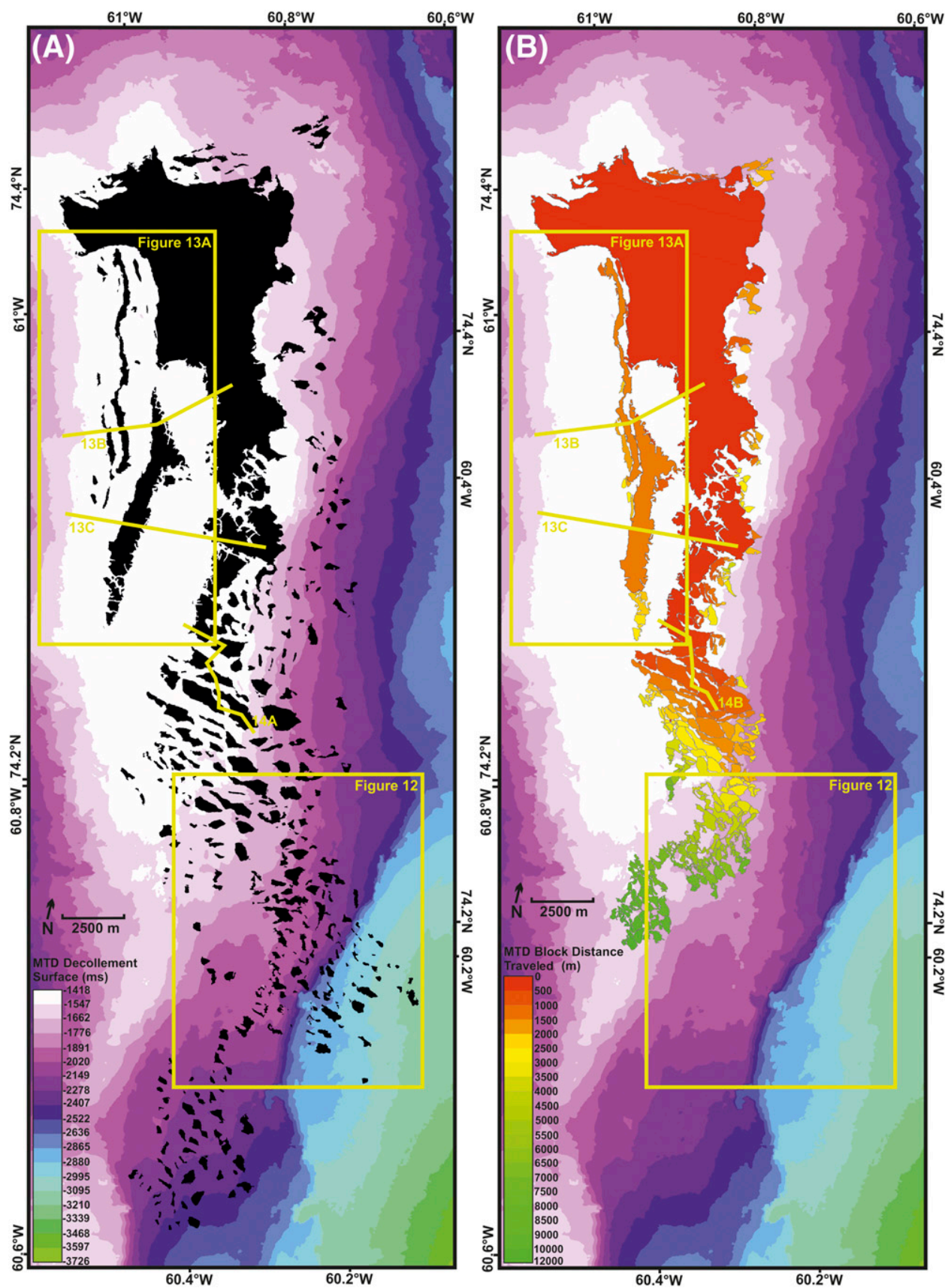

Figure 10. Landslide reconstruction. (A) A two-way time-structure map of the decollement surface overlaid by black polygons representing the modern-day location of individual reservoir blocks that are in excess of $30 \mathrm{~ms}(\sim 25-\mathrm{m}[\sim 82-\mathrm{ft}])$ thickness. The locations for Figures 12; 13A-C; and 14A are shown. (B) A two-way time-structure map of the decollement surface (legend within (A)) overlaid by polygons representing the reconstructed location of individual reservoir blocks in their presecondary sliding location. Each polygon is colored by the total distance traveled according to reconstruction. The locations for Figures 12; 13A-C; and 14B are shown. MTD = mass transport deposit.

decollement, which likely represent areas in which once-deposited reservoir has now been shed from the high. This implies the significant transport of sandy sediments into the deeper parts of the basin in which data quality, acoustic characteristics, and data availability do not allow mapping of the equivalent deposit. Thickness trends and internal reflections across multiple blocks, along with interconnecting block shapes, indicate that the reservoir was deposited along the MBR and adjacent to the large undeformed section 


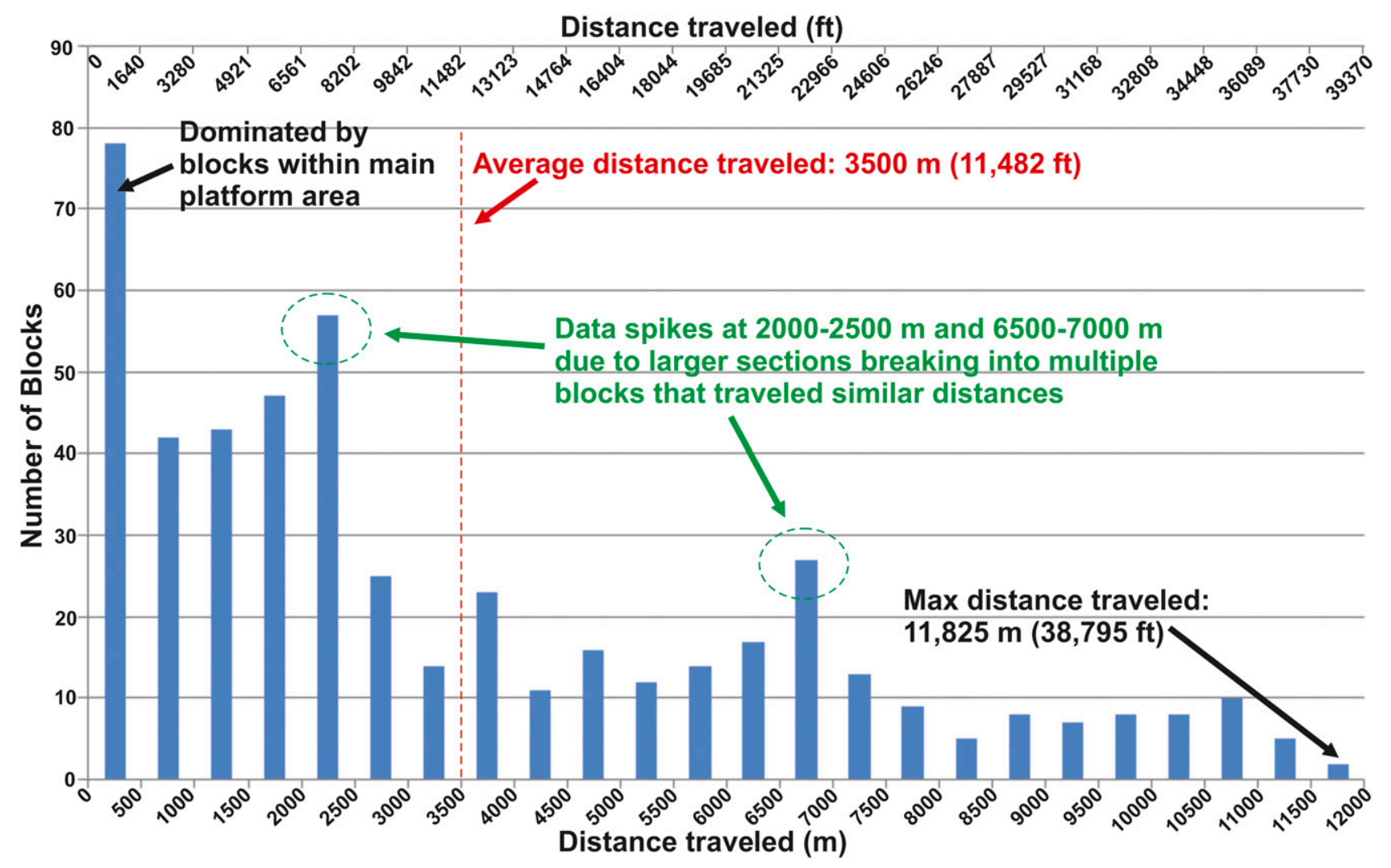

Figure 11. A histogram showing the distribution of block sliding distances calculated during the landslide reconstruction process. Max= maximum.

of the reservoir in the north (see the Data and Methods section). The blocks show a general trend of having been deposited close to the central axis of the northwest-southeast-trending MBR. The reconstructed reservoir map in Figure 10B is color coded by distance traveled caused by sliding. This highlights an increased distance of sliding in the southern section of the reservoir, along the strike of the MBR in the least dipping direction of the decollement surface (Figures 8, 10).

The maximum distance of block sliding was shown to be $11,825 \mathrm{~m}(38,795 \mathrm{ft})$ with an average slide distance of $3500 \mathrm{~m}(11,483 \mathrm{ft})$ (Figure 11). The dominance of the $0-500-\mathrm{m}(0-1640-\mathrm{ft})$ travel distance ( 78 blocks) is caused by small blocks that closely surround the large central reservoir block and are still within the flatter, platformlike area of the MBR. This causes the average travel distance to be reduced. Additional observations include two data spikes that are observed at 2000-2500-m (6562$8202-\mathrm{ft})$ and 6500-7000-m (21,325-22,965-ft) ranges. All of the blocks that traveled a distance over $10,000 \mathrm{~m}(>32,808 \mathrm{ft})$ are observed within the southernmost section of the reservoir, which may be because of a gentler slope gradient in this direction (axis of MBR) (causing the blocks not to disaggregate) (Figure 8) but could also, to some extent, be biased by the distribution of the available data set. It is possible that blocks exist outside of the data set, but is more likely that any blocks transported beyond the survey edge will have disintegrated because of an increased slope gradient (Figure 8) away from the MBR central axis and been redeposited as gravity flows in the deeper basin, as seen on the eastern flank (Figure 7).

Further analysis of the reconstruction over an area on the eastern flank depicts the flow directions for each of the reconstructed blocks (Figure 12). This process highlights two trends of motion. First, the areas of the reservoir directly above the MBR trend toward the southeast along strike of the dipping ridge. The blocks then move in a secondary trend as they reach the eastern edge of a narrowing MBR and slide eastward and down into the deeper MBG. It is unknown whether sliding in the two directions was separated by a period of no movement or a smooth continuation.

Within the southern section of the main reservoir block, two large areas do not show frequency or 


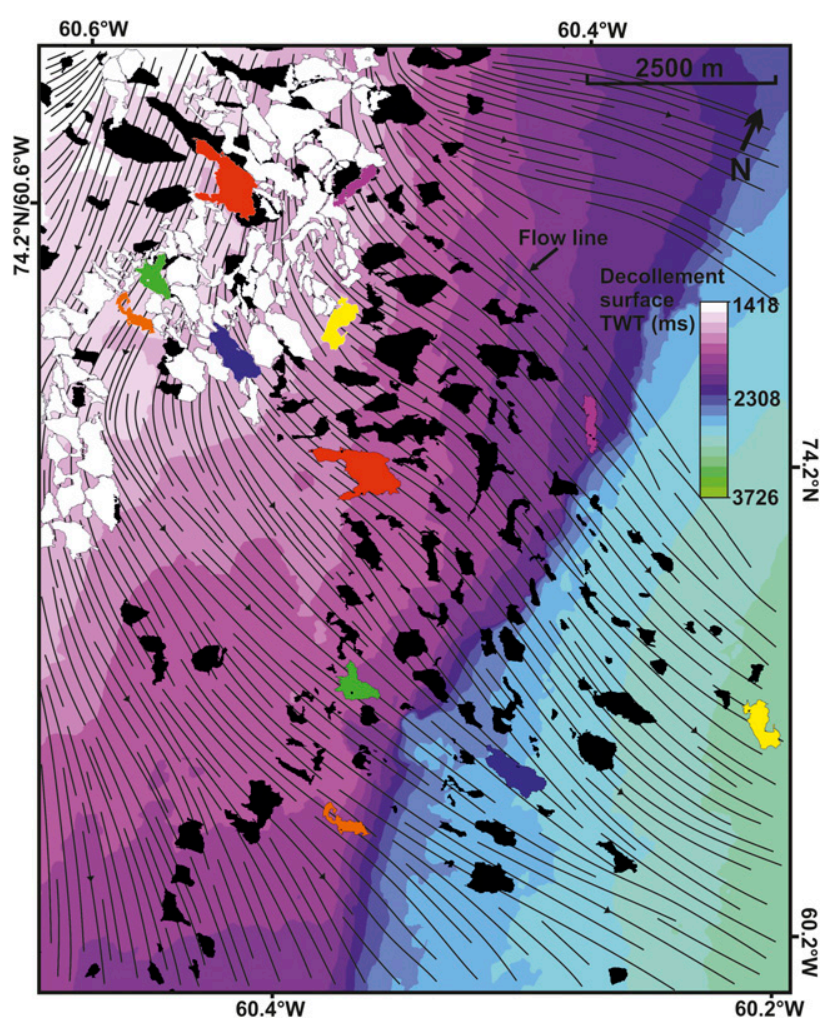

Figure 12. A two-way time (TWT)-structure map of the decollement surface overlaid by polygons representing the modernday location (black) and reconstructed location (white) of the reservoir blocks. Certain polygon pairs have been colored for comparison. Flow lines are shown between block polygon pair locations that represent the direction of movement and highlight a bidirectional trend during sliding. The map location and decollement surface legend are shown in Figure 10.

DHI responses and most likely do not contain reservoir (Figures 5, 10, 13). This is also suggested by an opposite amplitude response (hard event) across these sections compared to that of the reservoir blocks and by the absence of the velocity pushdown effect likely created by gas in the reservoir. The two sections are underlain by localized high areas that suggest increased elevation and perhaps nondeposition on the decollement surface during original reservoir deposition. The location of these high areas coincides with the crests of tilted fault blocks that exist beneath the MBR and consist of prerift stratigraphy (mega-unit H) (Figure 3) (Gregersen et al., 2013). The surrounding internal reflections within the reservoir are shown to thin and onlap onto the flanks of the localized highs (Figure 13).

Comparison of the two adjacent nonreservoir areas shows a differing relationship with the elongated reservoir block to the west (Figure 13). Within the southern section, the block looks to have slid away from the flank of the high, whereas the northern section of the elongated block is still directly adjacent to the high. This suggests that the whole block has not simply slid westward but has rotated clockwise by approximately $23^{\circ}$. Blocks are also shown to only exist above areas where the decollement is relatively flat, with no further blocks observed on the steeply dipping western flank of the MBR beyond the elongated reservoir blocks (Figure 13).

\section{Internal Stratigraphy of Landslide Blocks}

Completing the geometric landslide reconstruction process allows the presliding seismic characteristics of the reservoir to be assessed. This assessment removes the interblock areas along a seismic cross section (extracted along an MTD slide vector), juxtaposing the sections of the blocks, which were once laterally adjacent (Figure 14). This provides a view of the original depositional structure of the reservoir presliding, highlighting continuing internal stratification. The process can also help to highlight stratigraphic features that occur across multiple blocks, which may not be readily visible because of their present separation. The example highlights a central package within the reservoir response that are of lower amplitude to the under- and overlying sections. This package only exists within the two thicker reservoir areas shown in Figure 5B. Within this reconstructed package, several steeply dipping, oblique-sigmoidal reflections are observed that resemble clinoform features dipping toward the southeast (Figure 14).

\section{DISCUSSION}

The MTDs have a significant impact on the hydrocarbon industry by commonly serving as hydrocarbon seals (Alves et al., 2014; Sun et al., 2017) and by forming major reservoirs for several fields in the North Sea and Gulf of Mexico alone (Meckel, 2010). With less than $10 \%$ of MTDs worldwide being sandy, it is often difficult to differentiate between sandprone and shale-prone MTDs in seismic data, and it is often only after drilling a target that a sand-prone MTD interpretation can be made (Meckel, 2010). Here, seismic observations have identified the 
(A)

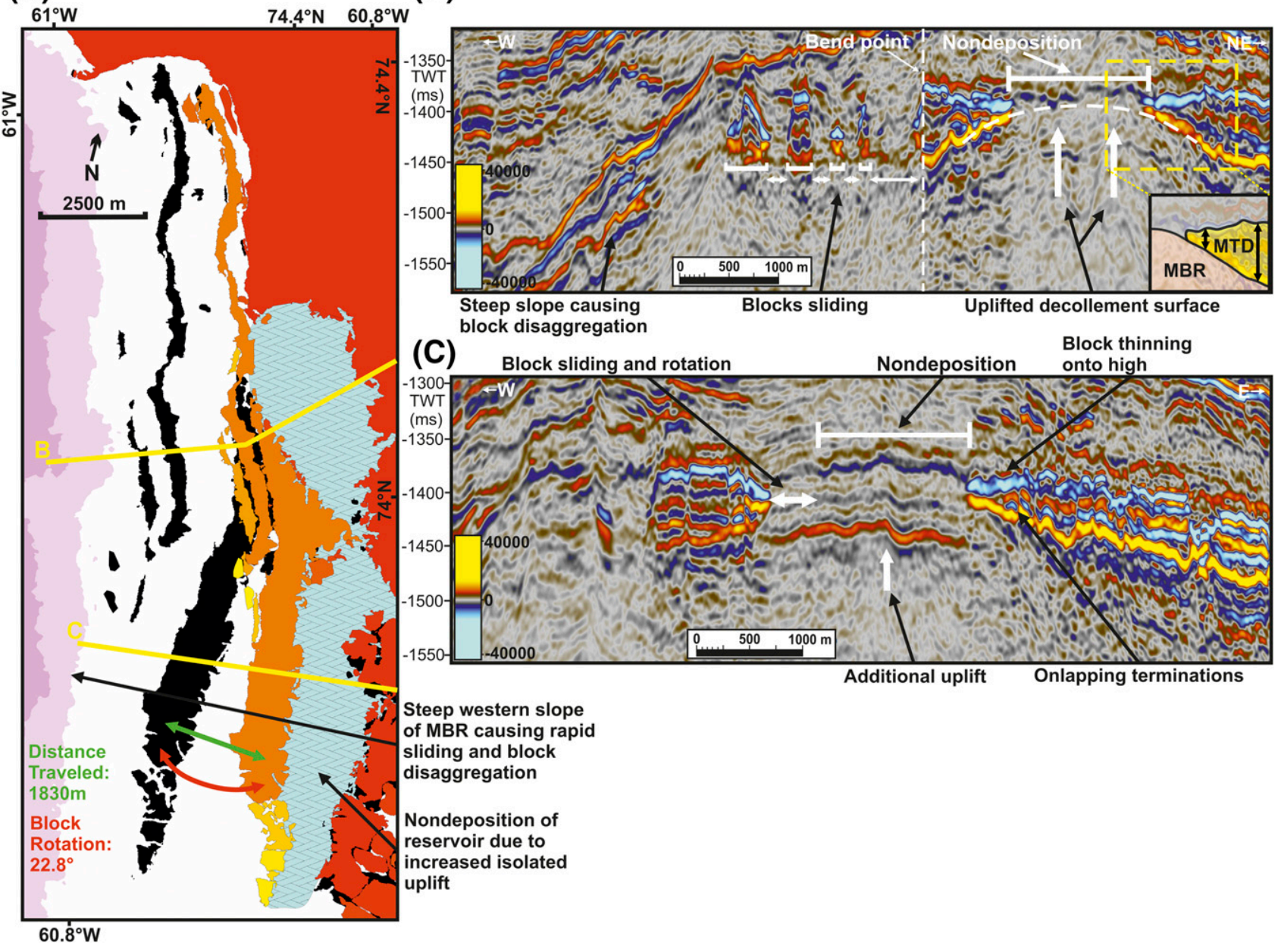

Figure 13. Areas of reservoir nondeposition. (A) A comparison of modern-day (black) and reconstructed (colored) reservoir block locations, shown on top of a two-way time (TWT)-structure map of the decollement surface. Areas of reservoir nondeposition are highlighted in blue. The map location and decollement surface legend are shown in Figure 10. (B) A seismic section showing the location of an uplifted platform on the decollement surface on which reservoir deposition did not occur. The schematic insert depicts the thinning of the reservoir against this uplifted high. The line location is shown in Figure 10. (C) A seismic section showing nondeposition and subsequent sliding of a reservoir block to suggest block rotation. The line location is shown in Figure 10. MBR = Melville Bay ridge; MTD = mass transport deposit.

presence of a sandy MTD consisting of gas-charged, highly porous blocks on the crest and eastern flank of the MBR (Figures 3, 4) that are of landslide origin having experienced postdepositional breakup and sliding. The package is clearly defined by high amplitudes and exists at the base of mega-unit D2 above a single decollement surface (the top reflection of mega-unit E [E1]) (Figure 3). Clear DHIs, frequency analysis via spectral decomposition, and estimations for velocity within the package all suggest a reservoir composed of highly porous sand that is likely gas charged, suggesting a working petroleum system within this area (Figures 4, 5).

\section{Reservoir Deposition and Deformation}

The basin and ridge topography, created by Cretaceous rifting, existed throughout the Paleogene and into the Neogene in the Melville Bay area (Whittaker et al., 1997; Gregersen et al., 2013). The MBR was likely a small, elongated emergent island extending from the northwestern Greenland mainland southward, creating a deep-water embayment above the MBG (Figures 2, 15). This is evidenced by onlap terminations of thick synrift deposits on the flank of the high as well as the increasing ridge height to the north (Figure 15). During periods of ridge uplift, no 


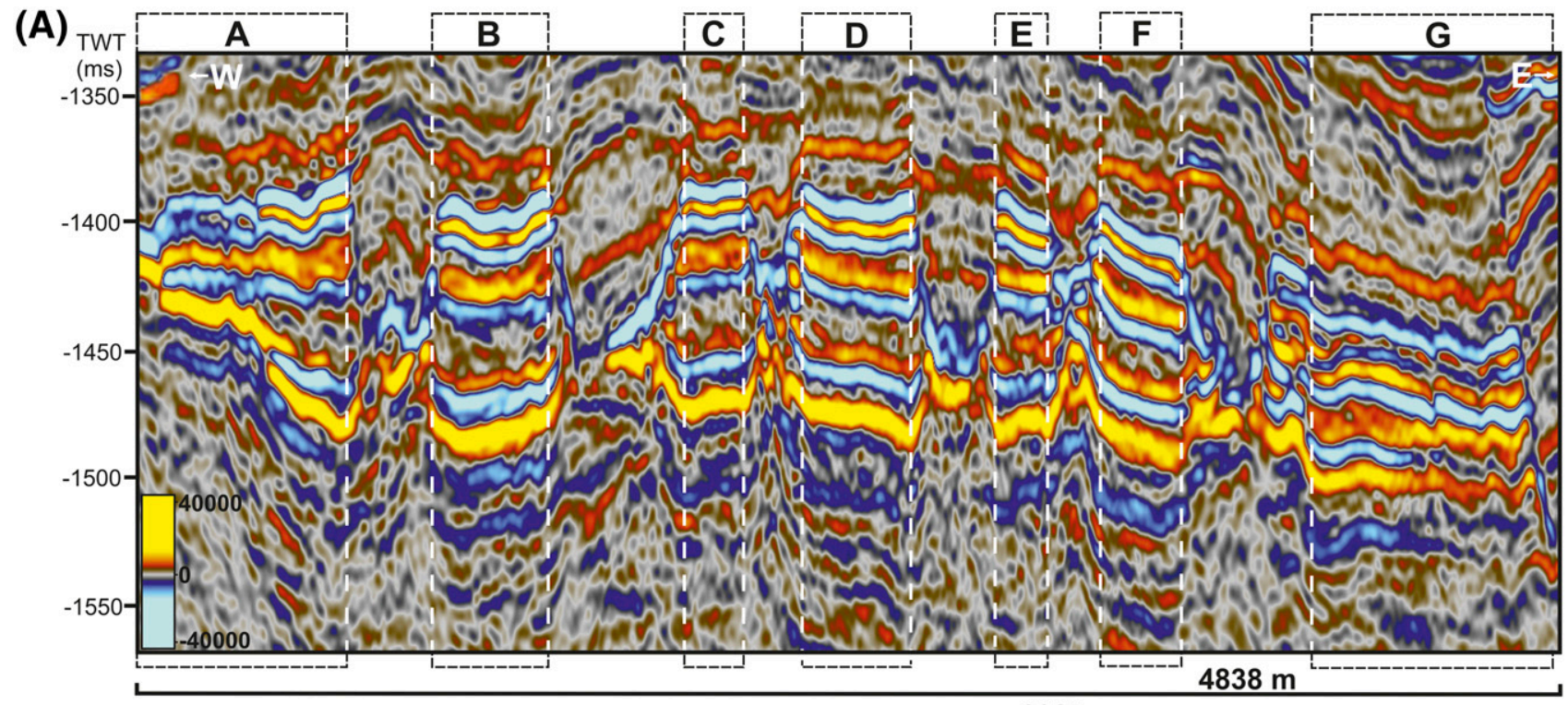

(B)

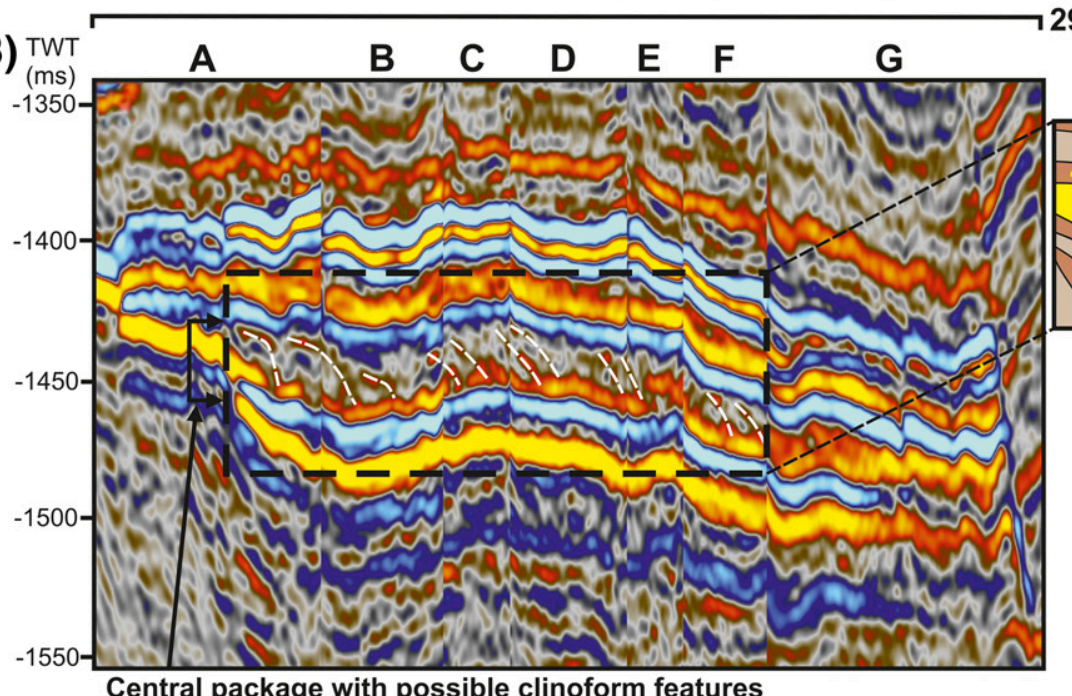

$2987 \mathrm{~m}$ Percentage shortening

through reconstruction: $61.7 \%$

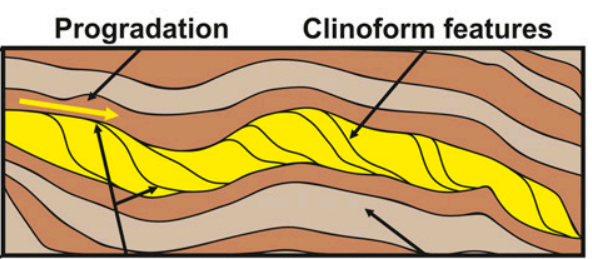

Top and toe sets Seismic response from below seismic thin stratified layers resolution

Figure 14. Reconstructed internal stratigraphy of mass transport deposit blocks. (A) A seismic section showing reservoir blocks that have been separated through sliding. The areas of the section selected for the reconstruction are shown. The location of the seismic line is shown in Figure 10A. (B) A reconstructed seismic section that shows the laterally consistent reservoir in its predeformation state. An internal section of the reservoir is highlighted and shown to contain clinoforms. These clinoform features are shown in the adjacent schematic diagram. The location of the seismic line is shown in Figure 10B. TWT = two-way time.

deposition occurred on the high and any sediment input would have bypassed into the deeper graben via gravity-driven processes (Gregersen et al., 2013) (Figure 16).

A period of net subsidence of the MBR allowed for the deposition of reservoir sands upon the ridge (Gregersen et al., 2016) (Figure 16). This likely occurred during the Eocene based on correlation of the base sand reflection (mega-unit E) on regional 2-D seismic data, with Eocene volcanics further south (Gregersen et al., 2013). The reservoir surrounds areas of nondeposition that exist above elevated areas on the ridge crest created by deep-seated tilted fault blocks (Figures 13, 15). This suggests sand deposition in a very shallow-marine environment, where restriction of deposition on these slightly more elevated areas is likely a result of being above the wave base.

Additional accommodation, possibly caused by localized faulting of the ridge, allowed the deposition of a localized thicker package within the reservoir that is observed during seismic reconstruction (Figure 14). This package is notably restricted to two 


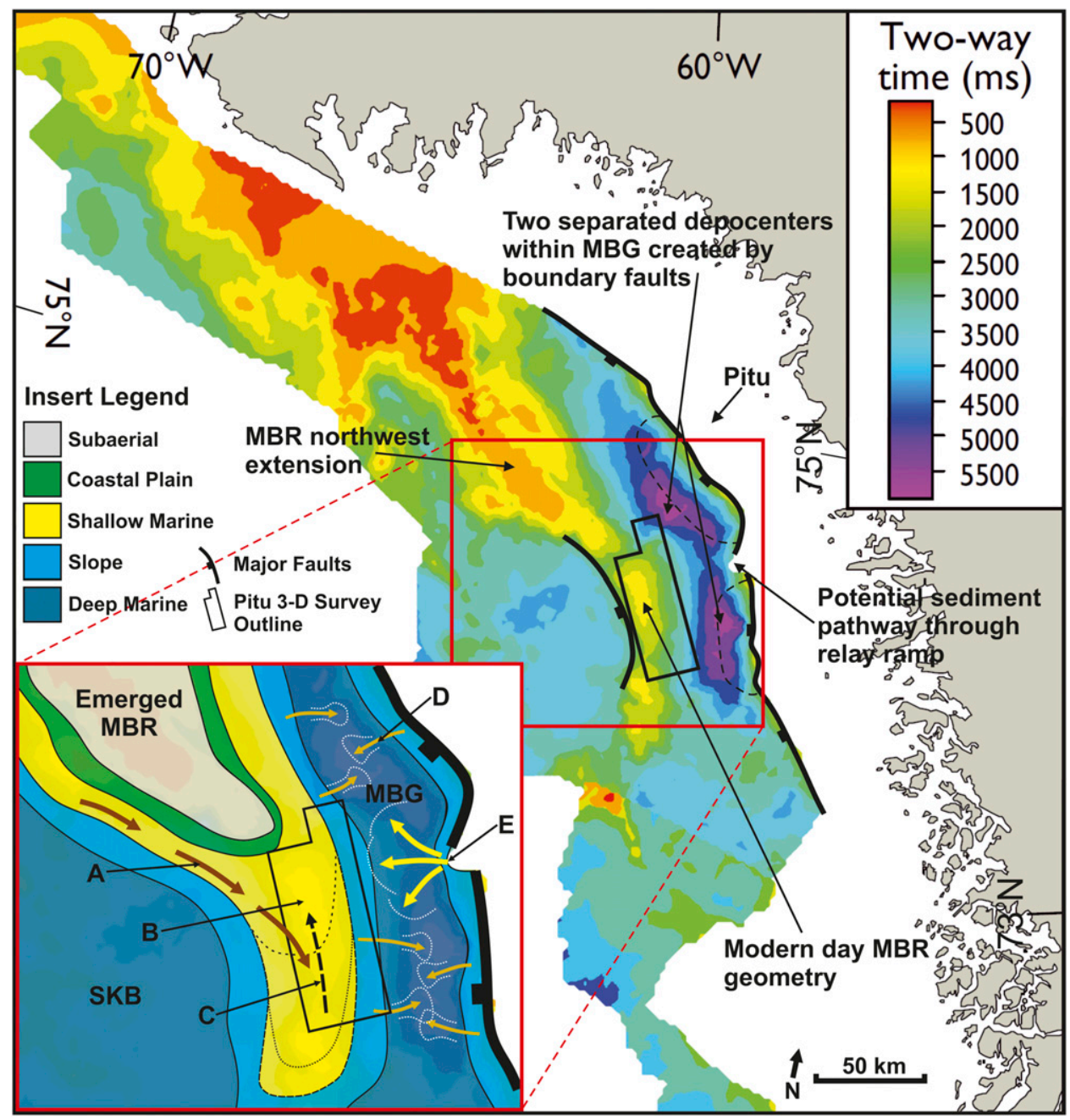

Figure 15. A two-way time-depth structure map down to horizon F1 (top reflection of mega-unit F) showing the distribution of basin depocenters and structural ridges (modified from Gregersen et al., 2016). Major bounding faults and the location of the Pitu seismic survey are shown. The enlarged insert map shows an interpretation of the gross depositional environments during reservoir deposition upon the ridge. The lettered labels are as follows: A, coast parallel sediment input; $B$, shallow-marine spit complex development along ridge axis; $C$, transgression of shallow-marine system; $D$, gravity flow deposition into deeper-marine environment; and $\mathrm{E}$, major sediment input into the graben center. $3-\mathrm{D}=$ three-dimensional; $\mathrm{MBG}=$ Melville Bay graben; $\mathrm{MBR}=$ Melville Bay ridge; SKB = South Kivioq Basin.

areas on the ridge top platform (thicker areas of reservoir in Figure 5B) and is seen to contain possible southeastwardly prograding clinoform foresets. These observations, along with the southeast sediment transport direction along the MBR axis extension, suggest the development of a spitlike complex that is restricted to the shallow waters on the ridge top (Figure 15). Sediment transport may have been driven by near-surface ocean currents in the wider Baffin Bay, moving sediment southeastward along the paleo-coastline before eventual progradation along the submerged MBR southerly nose. The thickness and preservation of the sands upon the ridge suggest a high-sediment supply (Swift, 1968) and would have likely led to the bypass and transport of excess sand into deeper waters via gravity-driven processes (Figure 15) (Raynal et al., 2009).

Candidate deposits that may contain these sediments have been observed by Knutz et al. (2012) and Gregersen et al. (2013) as submarine fans at the base of mega-unit D2 with sand transport downslope being the likely cause of canyon development at this horizon on the eastern flank of the MBR (Figure 7E). However, deep-marine clastics in the graben were still dominantly sourced from the Greenland mainland to the east, creating large packages of 
onlapping sediments that are observed at the basin center (Gregersen et al., 2016). The focal point for sediment input may have been a relay ramp between fault sections of the MBG boundary fault (Figure 15).

Major extension ended in Baffin Bay during the late Eocene-Oligocene (Oakey and Chalmers, 2012), and Melville Bay experienced thermal subsidence and deepening waters leading to the preservation of the reservoir sands. Relative sea-level rise forced a southeast-northwest transgression of the spit complex system (Figures 15, 16), leading to increased reservoir thicknesses to the northwest before a transition of the environment to deep-marine mud deposition (Figures 3, 4, 5B).

Soon after reservoir deposition and before the overlying muds were in place, the reservoir sands underwent significant deformation, leading to the mass redistribution of sediment from the ridge top to its upper flanks, resulting in the modern-day reservoir structure, characterized by a large number of intact, separated MTD blocks along with a larger stable reservoir section to the north (Figures 4, 16). The breakup and sliding of reservoir blocks was likely triggered by a southward tilt of the MBR, evidenced by the reconstructed flow directions (Figure 12). This tilt was either caused by renewed heterogeneous uplift along strike of the MBR (with a relative increased degree of uplift to the north) or increased subsidence to the south (Figure 16). This is also supported by the increased quantity and travel distance (some $>10 \mathrm{~km}$ [>6.2 mi]) of blocks southward (Figure 10). However, the southern slope represents the least dipping direction because it is along the southerly nose of the MBR (Figure 8). Therefore, the increased number of intact blocks may be because of preservation bias, with blocks down the steeper eastern and western ridge flanks having disintegrated.

The east-west-trending, low-amplitude features observed on the eastern flank of the MBR (Figures 5, 7) are likely to represent decollement surface deformation and extensional slumping, controlled by the location of faults (Figure 7). Low-amplitude zones within these features represent small extensional faults that facilitate deformation of the decollement surface (Figure 7B, C). The deformational features seem to mimic the shape of the sliding reservoir blocks seen along strike and were possibly caused by beneath-block deformation of decollement muds during sliding. It is possible that these features represent resting places for the blocks, thus creating an imprint or slide scar on the decollement surface before sliding further down the steepening slope and disaggregating (since the blocks themselves are not observed). This disaggregation caused much of the sliding reservoir sand to be redeposited by graben floor gravity flows (Knutz et al., 2012; Gregersen et al., 2013) or to be trapped in topographically controlled depocenters on the ridge slopes in features such as half grabens and canyons (Figures 7D, E; 16). The large volume of sediment shed from the high will have aided the development of the deep linear canyons that are observed trending into the MBG to the east (Figure 7E). Within these canyons, high positive seismic amplitudes (Figure 7E) likely represent redistributed reservoir sands.

The deformational features observed all suggest that reservoir deformation and preservation are controlled by the slope angle of the decollement (Figure 8). This angle is likely controlled by the uplift and resultant structure of the MBR along with the location of faults. Based on this, the system can be subdivided into four zones of deformation style that define the distribution and character of the reservoir sands (Figures 7D, 8).

1. Stable platform crest: postdepositional deformation and sliding not observed, likely bald high areas with reservoir onlap.

2. Mega-block sliding: shallow slope-induced breakup into blocks and sliding along a muddy decollement layer.

3. Slide scars and disaggregation: sliding reservoir blocks caused deformation of the underlying decollement muds before the disaggregation of sand blocks because of slope steepening (possibly controlled by fault locations).

4. Canyonization: erosional canyonization of the decollement surface caused by the continued downslope shedding of sediment; disaggregated sands deposit within canyon features.

These four deformational styles transition across areas of different dip angles seen across the modern-day decollement surface. However, it is the paleodip of the decollement surface during the period of deformation (Eocene) that would have had the controlling effect 

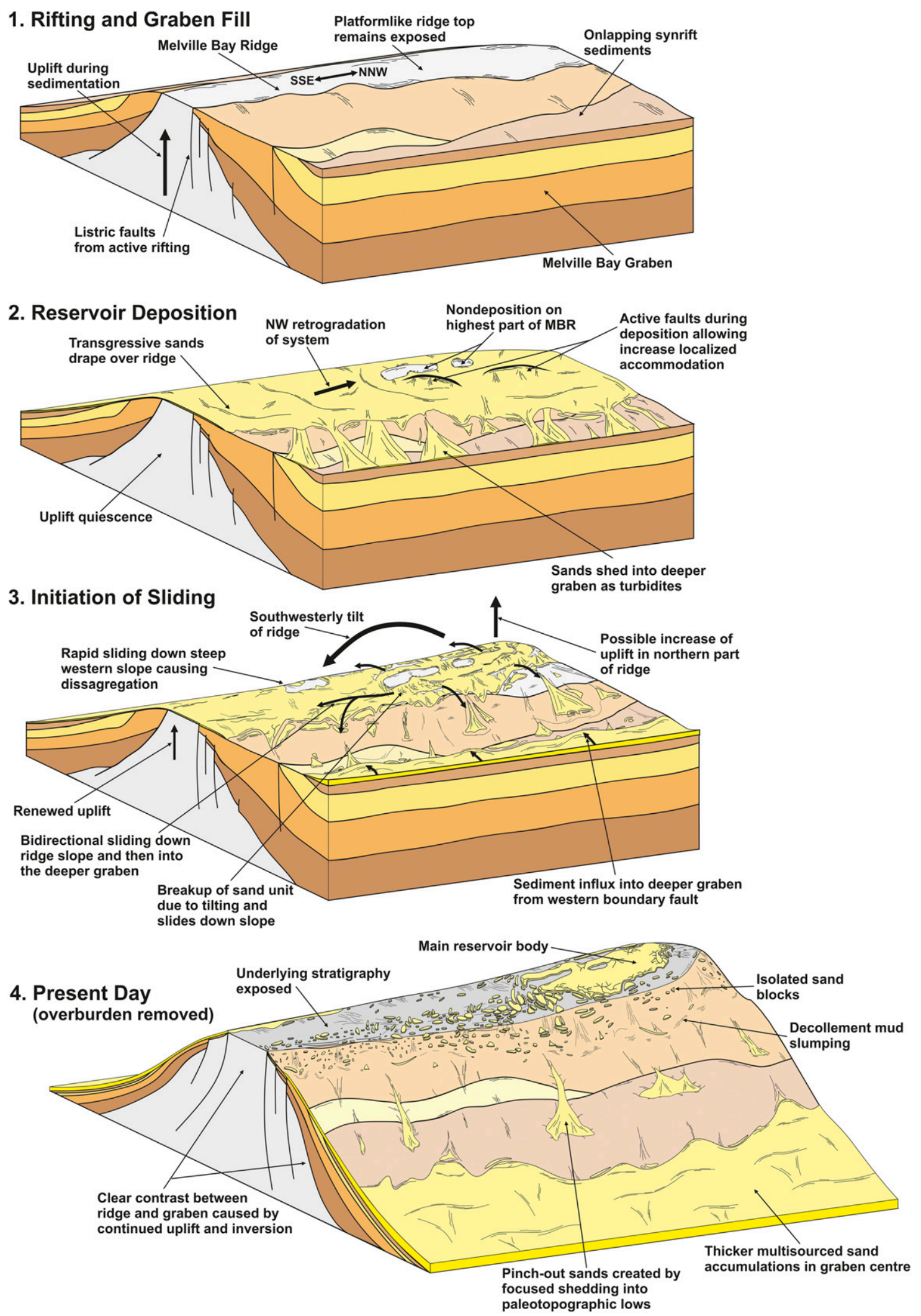

Figure 16. A series of schematic models that represent the depositional and structural development of the reservoir on the seabed above the uplifted Melville Bay ridge (MBR) and adjacent Melville Bay graben (models 1-3). Model 4 represents the modern-day reservoir distribution with the overburden removed. The models are not drawn to scale. 
Table 1. Summary Table of the Location, Lithology, Maximum Block Width, Maximum Block Height, and Run-Out Distance for This Study and Several Analogous Mass Transport Deposits

\begin{tabular}{|c|c|c|c|c|c|c|}
\hline No. & Location & Lithology & $\begin{array}{l}\text { Max. Block } \\
\text { Width, m (ft) }\end{array}$ & $\begin{array}{l}\text { Max. Block } \\
\text { Height, } m \text { (ft) }\end{array}$ & $\begin{array}{l}\text { Run-Out Distance of } \\
\text { Blocks, km (mi) }\end{array}$ & Reference \\
\hline 1 & $\begin{array}{l}\text { Melville Bay, Northwest } \\
\text { Greenland }\end{array}$ & Sand + mud & $1000(3280)$ & $80(262)$ & $12(7.5)$ & This study \\
\hline 2 & $\begin{array}{l}\text { Hikurangi Margin, New } \\
\text { Zealand }\end{array}$ & Mud & $18,000(59,040)$ & $1200(3936)$ & $40(24.9)$ & Collot et al. (2001) \\
\hline 3 & San Carlos, Mexico & Sand & $100(328)$ & $30(98)$ & $\sim<1(\sim<0.6)$ & Morris and Busby-Spera (1988) \\
\hline 4 & Southeast Crete & Carbonate & $100(328)$ & $64.5(212)$ & $\sim 2.5(\sim 1.6)$ & $\begin{array}{l}\text { Alves (2015) through } \\
\text { Alves and Lourenço (2010) }\end{array}$ \\
\hline 5 & $\begin{array}{l}\text { Southwest Labrador } \\
\text { Sea }\end{array}$ & Sand + mud & $6000(19,680)$ & $300(984)$ & $\sim 50(\sim 31.2)$ & Deptuck et al. (2007) \\
\hline 6 & Central North Sea & Carbonate & $1000(3280)$ & $170(558)$ & $200(124.6)$ & Soutter et al. (2018) \\
\hline 7 & $\begin{array}{l}\text { Espirito Santo Basin, } \\
\text { Brazil }\end{array}$ & Sand & $2400(7872)$ & $250(820)$ & $10(6.2)$ & $\begin{array}{l}\text { Omosanya and Alves (2013) } \\
\text { through Gamboa et al. (2011) }\end{array}$ \\
\hline 8 & $\begin{array}{l}\text { Taranaki Basin, New } \\
\text { Zealand }\end{array}$ & Sand + mud & $1000(3280)$ & $200(656)$ & $15(9.3)$ & Rusconi et al. (2018) \\
\hline 9 & Niger Delta, Nigeria & Sand + mud & $250(820)$ & $10(33)$ & $12(7.5)$ & Nissen et al. (1999) \\
\hline 10 & Offshore Morocco & Sand + mud & $4000(13,120)$ & $150(492)$ & $\sim>50(\sim>31.2)$ & Lee et al. (2004) \\
\hline 11 & Santos Basin, Brazil & Mud & $5000(16,400)$ & $350(1148)$ & $95(59.2)$ & Jackson (2011) \\
\hline 12 & $\begin{array}{l}\text { Faeroe-Shetland } \\
\text { Channel }\end{array}$ & Sand + mud & $70(230)$ & $18(59)$ & $25(15.6)$ & Kuijpers et al. (2001) \\
\hline 13 & Gela Basin, Italy & Sand + mud & $800(2624)$ & $10(33)$ & $9.1(5.7)$ & Minisini et al. (2007) \\
\hline
\end{tabular}

The reference for each example is shown in the table.

Abbreviation: Max. $=$ maximum.

on the modern-day reservoir distribution. It is difficult to estimate paleodip in an area dominated by deepwater hemipelagic sedimentation, a clastic supply dominantly from the east (Gregersen et al., 2013), and significant sediment erosion caused by recent glaciations (Figures 2, 3). Still, paleodip was likely similar or less than that observed today because uplift of the MBR is expected to have continued into the Neogene, increasing the slope angle postsliding (Oakey, 2005; Japsen et al., 2006; Knutz et al., 2015). Additionally, the main sliding vector toward the southeast aligning with the direction of lowest average dip at $0.41^{\circ}$ suggests that breakup and sliding of the reservoir commenced at a very low dip angle $\left(<0.5^{\circ}\right)$.

After the deformation of the reservoir sands and the full transition to a deep-marine setting during the late Eocene, a thick sequence of mud deposition occurred over both the basin and ridge. Mud deposition infilled between the separated reservoir blocks (evidenced by low-amplitude, flat-reflection geometries between blocks), suggesting deposition postreservoir deformation. These muds make up the lower section of the thick, polygonally faulted mega-unit D1 (Figures 3, 9).

The observed coincidence between faults extending subvertically from the block edge and the lower tips of polygonal faults (Figure 9) suggests that the reservoir blocks were a major factor in the development of the polygonal fault network above the MTD deposit. This occurred because of differences in compaction behavior between the sand blocks and infilled interblock muddy areas, which created a series of normal faults at the block edge (Figure 9). The compactional differences between mud and sandy block areas likely created subtle stress perturbations, which controlled the nucleation of polygonal faults into the overburden. This process potentially created a vertical fluid pathway constrained at the block edge from the reservoir to shallower stratigraphy, potentially representing a significant exploration risk, although polygonal fault planes are only thought to 
Max. Block Thickness vs. Max. Block Width

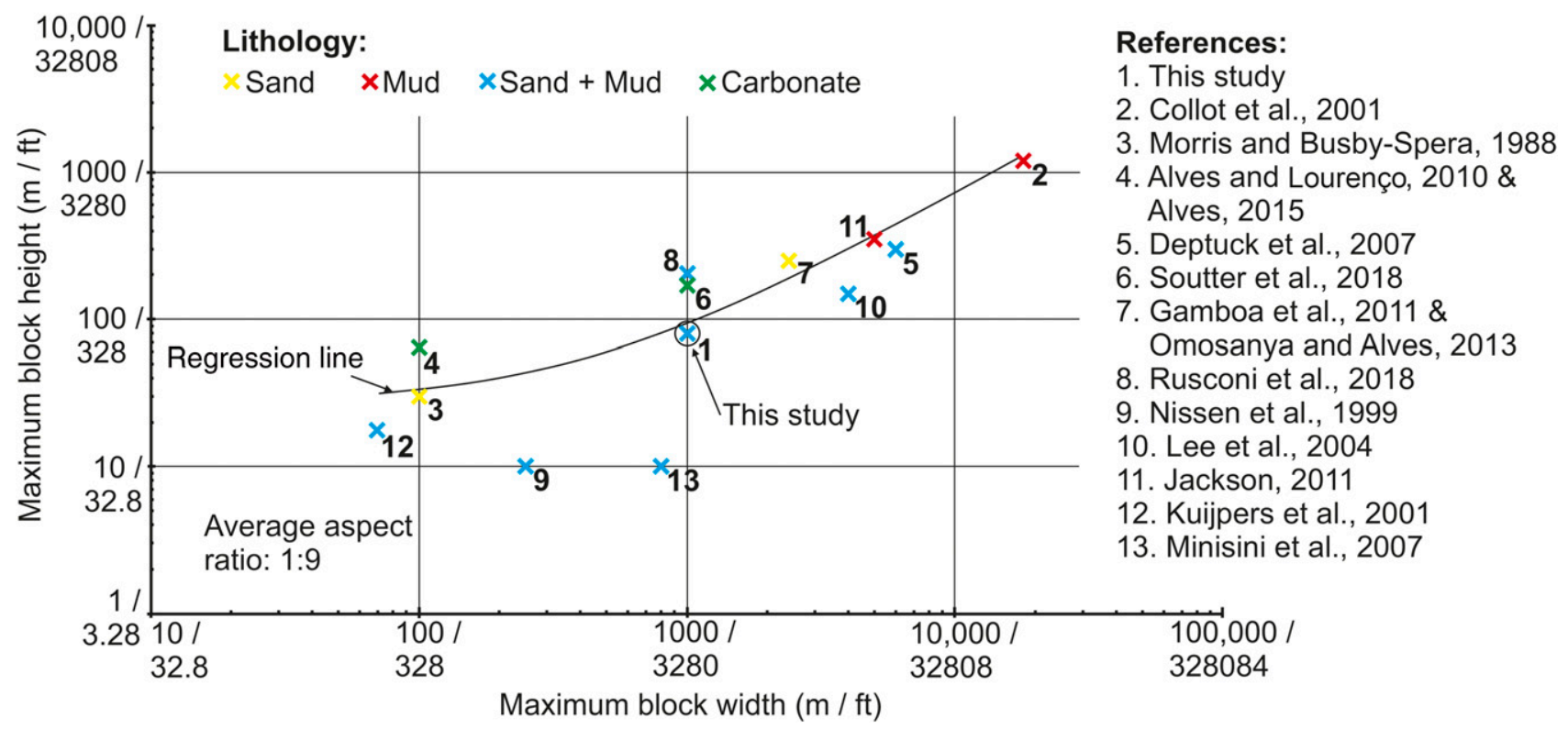

Figure 17. A graph showing the relationship between the maximum (Max.) block height and the Max. block width for this study and mass transport deposit (MTD) blocks observed within analog MTDs. These data are shown in Table 1, and references are shown in the figure.

conduct fluids when actively forming, and polygonal faulted claystones are extremely effective seals in much of the North Sea Basin (Cartwright et al., 2007; Goulty, 2012).

\section{Mechanisms of Sliding}

The deposition of MTDs commonly results in a deformed mass of partly disaggregated sediment, which may lack coherent primary depositional structures, and is typically characterized by chaotic internal seismic reflections (Shipp et al., 2011). These gravitational deposits, however, are capable of transporting large clasts or blocks within the flow, which often maintain their primary structure and internal stratification (Alves, 2015; Jackson, 2011).

The phenomenon of relatively undeformed siliciclastic "mega-blocks" within a submarine slide deposit has been observed in different parts of the world (Table 1); examples include the northern Hikurangi Margin, New Zealand, where internally bedded slide blocks have been transported for greater than $40 \mathrm{~km}$ (>24.9 mi) (Collot et al., 2001); the Hopedale-Makkovik failure complex, southwest
Labrador Sea, which contains angular blocks up to 6 $\mathrm{km}(3.7 \mathrm{mi})$ across with well-preserved internal stratification (Deptuck et al., 2007); and the internally undeformed slide blocks of the lower conglomerate sandstone that reach thicknesses of $30 \mathrm{~m}$ (98 ft) and widths up to $100 \mathrm{~m}(328 \mathrm{ft})$, found within basal canyon fill of the Upper Cretaceous Rosario Formation, Mexico (Morris and Busby-Spera, 1988).

The enigma of the MTD studied here is the apparent lack of transporting flow, with blocks sliding downslope as independent rafts of sediment, not confined or hosted within a more typical debris flow as seen in the majority of other block-containing MTDs (Table 1) (Deptuck et al., 2007; Jackson, 2011; Alves, 2015). This is evidenced by areas between blocks being infilled by hemipelagic sedimentation postsliding (Figure 4). Despite this, the blocks have still managed to maintain their gross depositional structure throughout the processes of breakup and sliding up to and greater than distances of $10 \mathrm{~km}$ (>6.2 mi). This is evidenced by the large, angular, sandy reservoir blocks along with the apparently unaffected internal stratification of the blocks postsliding at least on a seismic scale (Figures 4, 5). This suggests that slide momentum and block cohesion during sliding can occur independently and without containment in a typical 
(A)
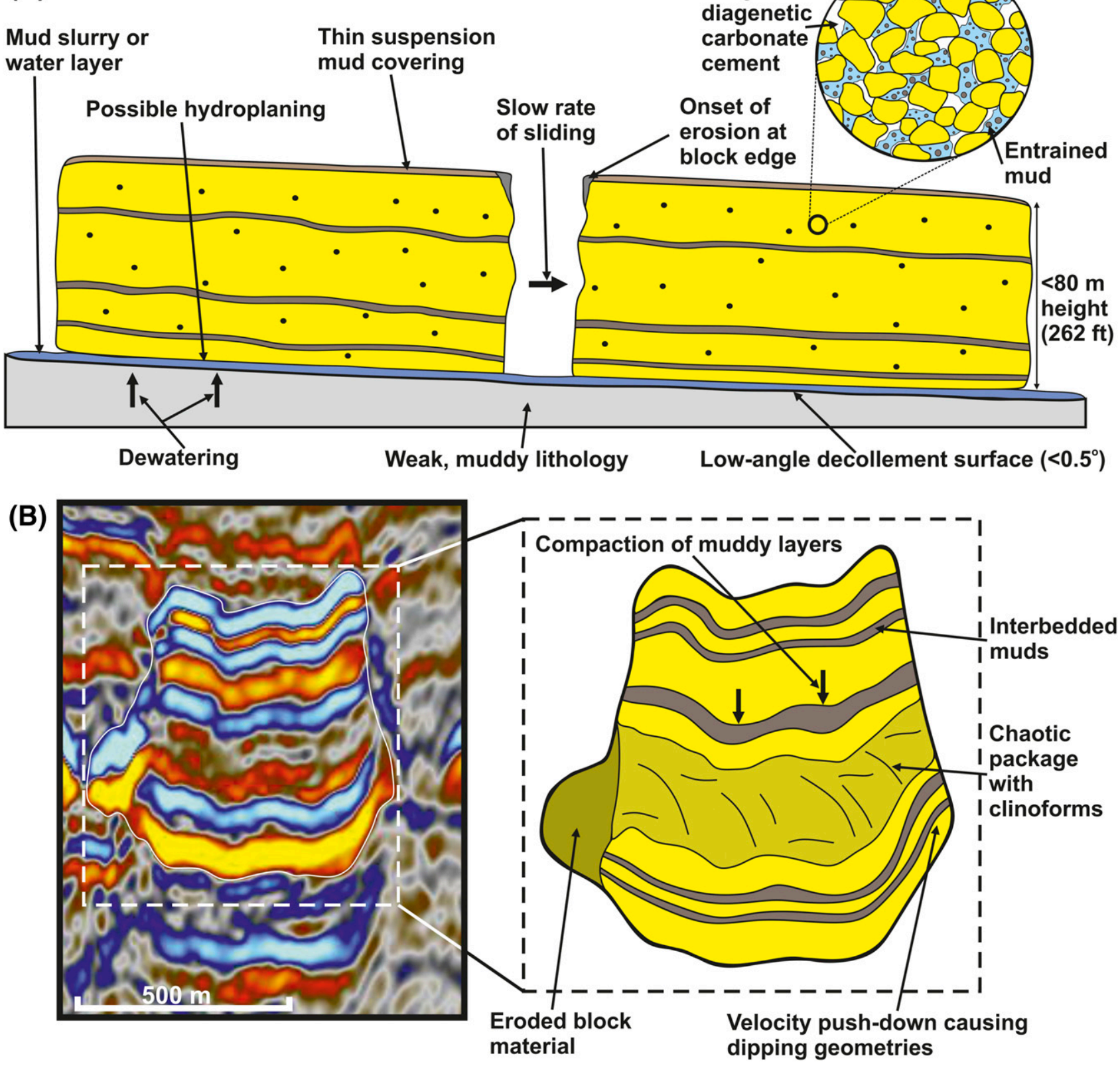

Figure 18. Mechanisms of sliding and block coherency and the internal stratification of the reservoir. (A) A schematic diagram showing the potential factors that led to coherent sliding of reservoir sands along the decollement surface. (B) A schematic interpretation of the internal stratigraphy within a separated reservoir block (shown on seismic section). The location of the seismic section is shown in Figure 6.

cohesive debris flow. Although the more typical confining flow is not observed, the similarities in block size, distribution, and run-out length to other MTD analogs (Figure 17; Table 1) supports the conclusion that similar gravitational processes, including the downslope coherent sliding of reservoir facies, led to the modern-day structure and distribution of the MTD studied here.
The similarity of this MTD to other analogs is highlighted by its maximum block size (maximum block width vs. maximum block height) plotting within a data trend that strongly suggests that increased block width commonly coincides with increased block height within MTDs (Figure 17). The blocks from this MTD plot within the center of the distribution; therefore, it could be argued that blocks 


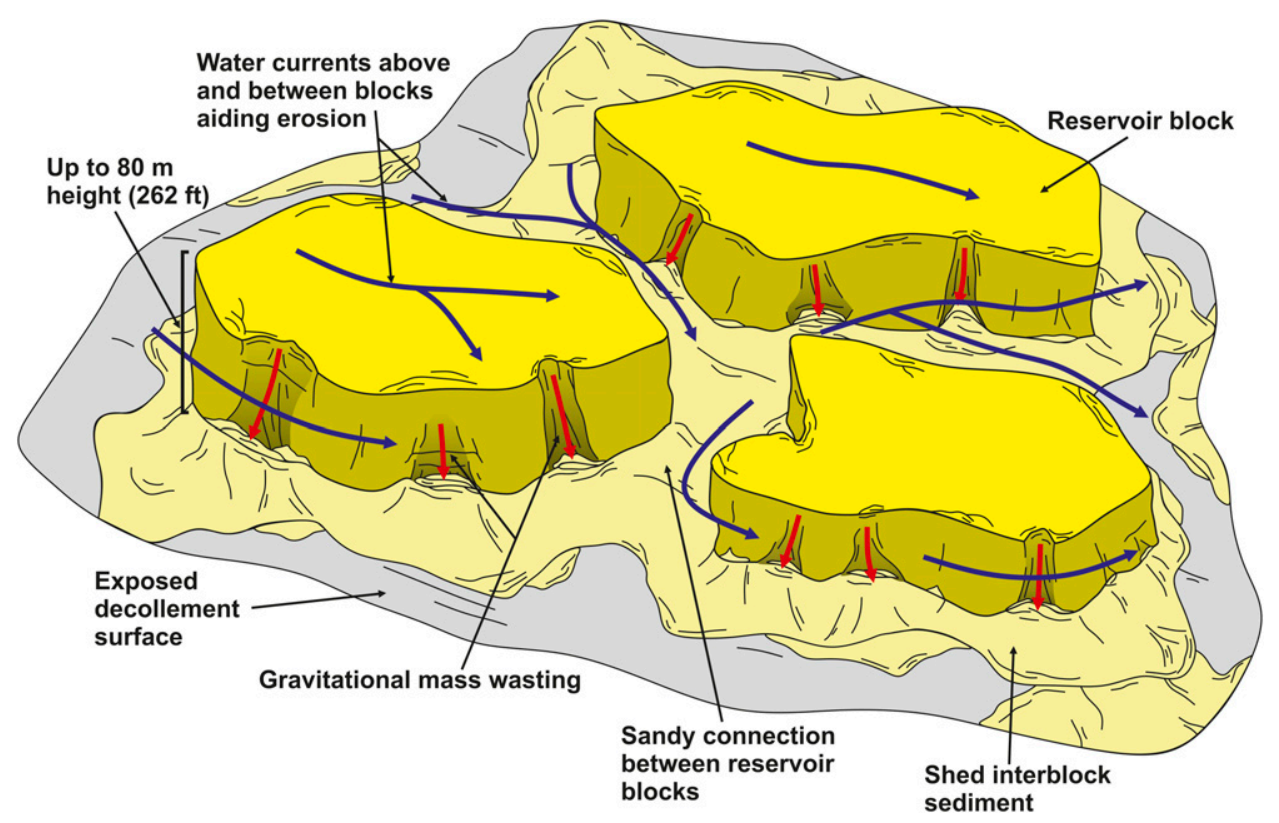

Figure 19. A schematic three-dimensional diagram showing water current and gravity-driven erosional collapse of sediment from the edges of angular reservoir blocks exposed on the seabed. This eroded sediment possibly creates sandy connections between separated reservoir blocks.

observed here represent a somewhat average example with regard to block size in MTDs.

Without the surrounding coherency and sliding lubrication provided by confinement within a larger debris flow, coherency of the blocks within this MTD was likely maintained and impacted by differing factors. First, the decollement surface itself would have provided a lubricated and smooth surface for the blocks to slide along (most likely a muddy horizon). This surface represents an unconformity above the underlying mega-units $\mathrm{E}$ and $\mathrm{F}$ (Figure 3), which are interpreted to be dominated by fine-grained claystones (Figure 18) (Gregersen et al., 2013). This weak, high-water-content lithology may have led to the development of a thin, subseismic veneer of mud slurry or a low-viscosity water layer (Prior et al., 1984) upon the decollement surface. In that scenario, a basal lubricating layer will reduce basal drag during sliding, increasing both block coherency and run-out distance while maintaining momentum. The underlying lubricating layer may also have caused blocks to hydroplane and decouple from the underlying surface during sliding; however, the probable slow speed of sliding makes hydroplaning less likely (Mohrig et al., 1998; Harbitz et al., 2003).

Slow, creeplike sliding would have reduced the attrition of the layered sediments, leading to a maintained primary depositional structure (Masson et al.,
1996). The rate of sliding is most likely controlled by the decollement angle (Kehle, 1970) (Figure 8). This may be the reason why no reservoir blocks are observed beyond the platform edge in areas where the decollement slope dip angle increases significantly $\left(>4^{\circ}\right)$ (Figure 8). Increasing slope angle away from the ridge axis, or at fault locations, would promote faster sliding, disaggregation, and shedding of sediments into the deeper basin (Figures 7, 8, 16). Along the ridge axis, however, the slide-triggering tilt of the MBR caused either by differential uplift or subsidence along strike (northwest-southeast) (Gregersen et al., 2013), would have likely only created a decollement surface tilt of less than $0.5^{\circ}$ (Figures 8,18 ). This low angle is commonly thought to be enough to facilitate sliding of marine sediments (Harbitz et al., 2003; Kvalstad et al., 2005) but remains low enough to maintain a slow sliding speed. Furthermore, the large scale of the blocks may provide protection to internal strata from disaggregation at the block edges (Morris and Busby-Spera, 1988; Alves, 2015). This protection may have occurred as larger slide blocks broke away from the main platform section and slid as one before subsequently breaking up into smaller blocks, as seen in Collot et al. (2001) (Figure 11).

Block coherency may have also been promoted by the internal stratification of the reservoir, evidenced 


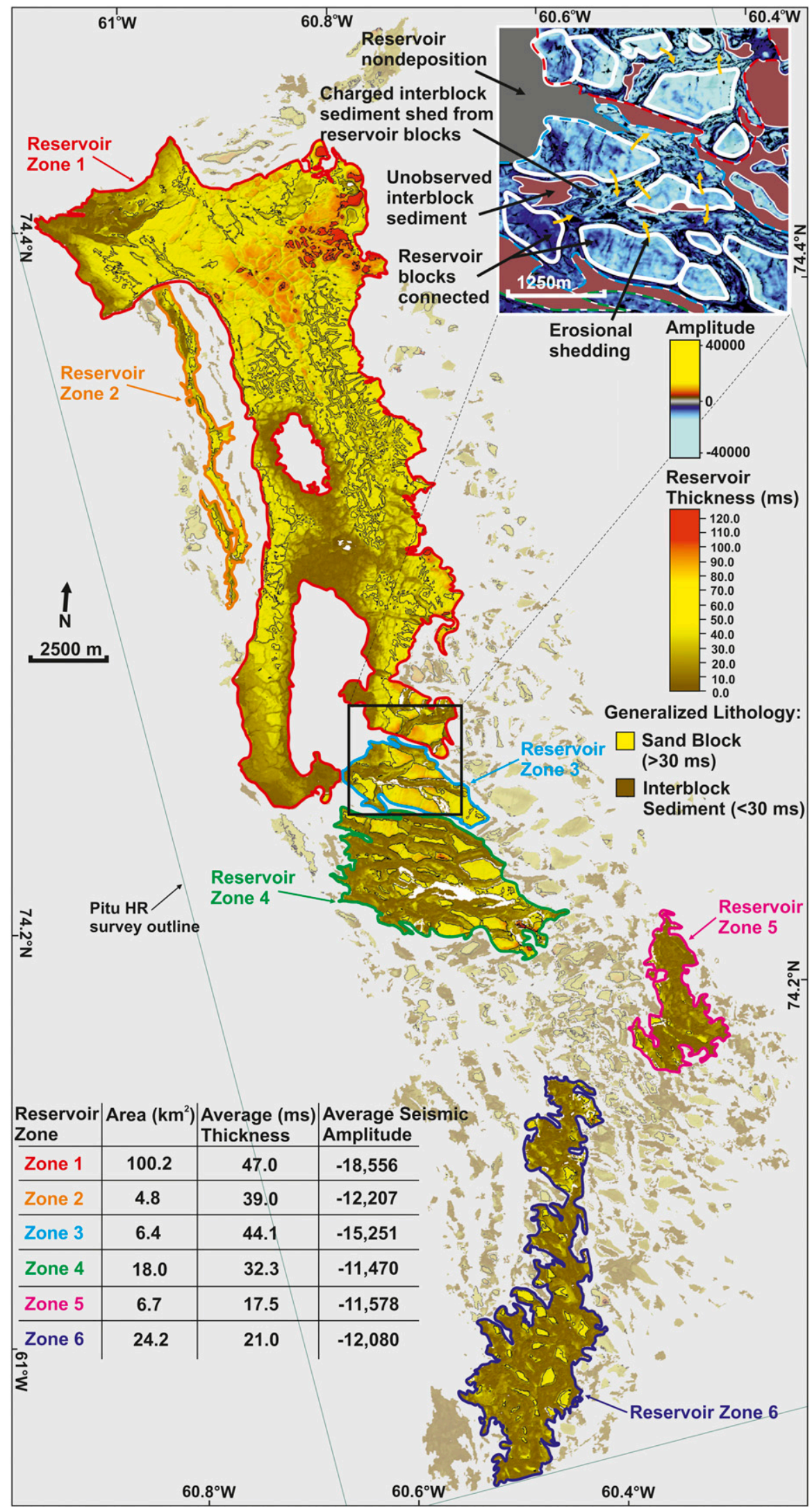


by bright seismic reflections within the reservoir package (Figures 4,18 ). This heterogeneity suggests that the reservoir contains muddy layers that will have experienced a degree of compaction and dewatering because of the thickness of the reservoir (Figure 18). This compaction would have increased the shear strength of these mud layers, which in turn would increase the stability of the reservoir block. Additionally, these mud layers, along with mud entrained into the reservoir sands, would have caused the sediment to become more cohesive and may also have helped block stability during sliding (Figure 18) (Le Hir et al., 2011). Furthermore, the environment transition into a deep-marine setting during the time of sliding may have caused slight burial of the reservoir by a hemipelagic mud drape. The covering of sand beds with thin layers of muddy sediment has been proven to enhance the coherency of the beds. This is because of silt grains plugging the pore space of sand beds and reducing the inflow in the bed, leading to a reduction in erosion and increased bed stability (Bartzke et al., 2013). However, any burial would have been minimal because of the short time between deposition and sliding, evidenced by the lack of slide-related deformation of the overburden.

Finally, early-onset carbonate cementation may have occurred within the reservoir because of the potential deposition of shelly carbonate material within the reservoir sands (Figure 18). Grain cementation would likely reduce the porosity of the sands but increase the shear strength of the sediment package, causing it to become more stable and resist collapse during sliding (Dyke and Dobereiner, 1991). Any cementation would however be slight because the fluid effect is strong, implying low acoustic rigidity.

\section{Implications for Reservoir Connectivity}

Postdepositional breakup and sliding has caused much of the reservoir to exist as distributed MTD blocks. The potential disconnection between these blocks may have a major impact on hydrocarbon extraction efforts, causing much of the reservoir to be uneconomic. However, the distribution of DHIs across all observed MTD blocks and within the interblock areas (Figures 4, 5, 6) suggest that gas has reached all parts of the reservoir. Because gas charging is thought to have occurred after the deformation and burial of the reservoir (to allow the seal to be in place), this may suggest that the isolated reservoir blocks are connected to allow migration.

However, source rocks within the Melville Bay area are likely to exist within Upper Cretaceous (Cenomanian and Turonian) stratigraphy (megaunit F) (Whittaker et al., 1997; Planke et al., 2009; Gregersen et al., 2013), the sediments that directly underlie the majority of the reservoir, updip from potential deeper-source kitchens in the MBG and South Kivioq Basin to the west and east, respectively (Figure 3). This connection between source rocks and the overlying reservoir would allow for updip migration into the MBR and subsequent upward migration and charging of all overlying reservoir sands. Therefore, a connection between distributed MTD blocks is likely not required to create the distribution of gas observed. It is more likely that any connectivity between MTD blocks is restricted to areas containing interblock sediments that have been mapped (Figures 5, 6). This sediment shows similar frequency and DHI responses on seismic data to the thicker reservoir blocks and likely represents gas-charged sands (Figures 5, 6). It was most likely deposited because of syn- and postslide block exposure at the seabed before seal coverage and gas charging. The edges of the reservoir sections would have resembled up to 80-m (262-ft)-tall cliffs with vast, deep areas between the blocks. This varied seabed topography, along with poorly consolidated sediment, would have promoted cliff edge erosion and gravitational collapse that was likely aided by current flow. This block-edge erosion is evidenced by the seismic geometry of the reservoir blocks (Figure 6) and is also depicted in

Figure 20. Interpreted zones suitable for exploration targeting because of potential cross-block communication provided by interblock sediment. The insert map shows a seismic amplitude extraction on the top reservoir surface that depicts the similar seismic amplitude of both the reservoir blocks and the interblock sediment that may create these cross-block connections. The map also indicates areas of interblock sediment nondeposition or erosion. The table inset within the figure shows the area (square kilometers), average thickness (milliseconds), and average seismic amplitude for each of the six highlighted reservoir zones. 
schematic form in Figure 19, showing the erosional collapse of sediment from the cliff edge caused by exposure. However, because of the angular nature of reservoir blocks (Figure 10), erosion over much of the reservoir is likely to be minimal or below seismic resolution, with more significant erosion confined to blocks within areas defined by reservoir zones in Figure 20.

Within these zones, eroded block sediment was deposited adjacent to the block edge, upon the exposed decollement surface (Figures 6, 19), most likely during and after sliding, allowing for deposition to be relatively widespread around the block edges. This led to the creation of a sandy connection between separated reservoir blocks, which may provide widespread reservoir communication.

However, this sandy connection and potential reservoir communication may only exist within the identified reservoir zones (Figure 20) because charged interblock sediment is not observed in other areas (Figures 5, 6, 19, 20). This absence may be caused by sediment shedding occurring only in certain areas or caused by postdepositional erosion of the interblock sediment. Also, because of the slow rate of sliding as well as the transition of the system into a deepermarine environment, fine-grained hemipelagic sediment may have become entrained into the interblock sands. This would reduce reservoir quality and potentially restrict both hydrocarbon charge and the fluid amplitude response. Overall, the sporadic absence of the reservoir-connecting sediment suggests that significant areas of the reservoir will remain disconnected.

Nevertheless, large areas of the reservoir do contain interblock sediment and are potentially in pressure communication. These areas have been divided into separate zones that are most suitable for exploration targeting (Figure 20). The six most connected zones cover an area of $160.3 \mathrm{~km}^{2}\left(62 \mathrm{mi}^{2}\right)$ with an average thickness of $33.5 \mathrm{~ms}$ (28 $\mathrm{m}$ [92 ft]). The remaining unknowns regarding interblock infill creating block connection increase exploration risk significantly. However, a large part of the selected reservoir zone area exists within zone 1 , which is the main reservoir block in its original depositional location. This block covers an area of $100.2 \mathrm{~km}^{2}$ (39 $\mathrm{mi}^{2}$ ) with an average thickness of $47 \mathrm{~ms}$ (40 m [131 $\mathrm{ft}]$ ) and may provide fewer production issues than the other selected surrounding zones.

\section{CONCLUSION}

Seismic investigations show an MTD prospect that displays acoustic and velocity characteristics consistent with thick gas-charged sands intercalated with mudstone layers. Reservoir structure shows landslide characteristics with much of the reservoir consisting of intact MTD blocks, which have slid downslope as independent rafts of sediment, not confined or hosted within a more typical debris flow. Sliding is interpreted to have occurred slowly and soon after deposition, with sediment coherency during sliding likely being aided by lithological and diagenetic characteristics as well as lubrication along a mud slurry or water layer upon the decollement surface. The reconstruction of 499 reservoir blocks provided evidence for basin development and postrift tectonic adjustments. The process identified a bidirectional sliding motion that suggests rejuvenation and a southward tilt of the MBR, which was likely the trigger of reservoir breakup and sliding. The process also provided evidence for the source of reservoir sands from the northwest, which were likely deposited within a shallow-marine transgressional spit complex at the southern end of an elongated emergent island created by the uplifted MBR during the Eocene.

The mechanisms of sliding along a low-angled decollement, along with the maintained sediment coherency during deformation, provide a high-quality analog of postdepositional breakup and sliding of reservoir facies. Furthermore, clear DHIs and velocity pushdown effects serve to calibrate MTD lithology and fluid content and are evidence of a working petroleum system. Overall, the reservoir has significant exploration potential focused around the large 100.2 $\mathrm{km}^{2}$ (39 $\mathrm{mi}^{2}$ ) main reservoir block (zone 1). However, any exploration considerations of the wider reservoir area must consider substantial development challenges linked to the separation and isolation of reservoir sections, as well as the additional uncertainty of interblock sediment connectivity.

\section{REFERENCES CITED}

Aksu, A. E., and J. W. Piper, 1987, Late Quaternary sedimentation in Baffin Bay: Canadian Journal of Earth Sciences, v. 24, no. 9, p. 1833-1846, doi:10.1139/e87-174.

Alves, T. M., 2015, Submarine slide blocks and associated soft-sediment deformation in deep-water basins: A review: 
Marine and Petroleum Geology, v. 67, p. 262-285, doi: 10.1016/j.marpetgeo.2015.05.010.

Alves, T. M., K. Kurtev, G. F. Moore, and M. Strasser, 2014, Assessing the internal character, reservoir potential, and seal competence of mass-transport deposits using seismic texture: A geophysical and petrophysical approach: AAPG Bulletin, v. 98, no. 4, p. 793-824, doi:10.1306 /09121313117.

Alves, T. M., and S. D. N. Lourenço, 2010, Geomorphologic features related to gravitational collapse: Submarine landsliding to lateral spreading on a Late MioceneQuaternary slope (SE Crete, eastern Mediterranean): Geomorphology, v. 123, no. 1-2, p. 13-33, doi:10.1016 /j.geomorph.2010.04.030.

Bartzke, G., K. R. Bryan, C. A. Pilditch, and K. Huhn, 2013, On the stabilizing influence of silt on sand beds: Journal of Sedimentary Research, v. 83, no. 8, p. 691-703, doi: $10.2110 /$ jsr.2013.57.

Bojesen-Koefoed, J. A., F. G. Christiansen, H. Peter Nytoft, and A. K. Pedersen, 1999, Oil seepage onshore West Greenland: Evidence of multiple source rocks and oil mixing, in A. J. Fleet and S. A. R. Boldy, eds., Petroleum geology of northwest Europe: Proceedings of the 5th Conference: Geological Society, London, Petroleum Geology Conference Series 1999, v. 5, p. 305-314, doi: 10.1144/0050305.

Butler, R. W. H., and J. P. Turner, 2010, Gravitational collapse at continental margins: Products and processes; An introduction: Journal of the Geological Society, v. 167, no. 3, p. 569-570, doi:10.1144/0016-76492010-003.

Cartwright, J., M. Huuse, and A. Aplin, 2007, Seal bypass systems: AAPG Bulletin, v. 91, no. 8, p. 1141-1166, doi: 10.1306/04090705181.

Cartwright, J., D. James, and A. Bolton, 2003, The genesis of polygonal fault systems: A review, in P. Van Rensbergen, R. R. Hillis, A. J. Maltman, and C. K. Morley, eds., Subsurface sediment mobilization: Geological Society, London, Special Publications, v. 216, p. 223-243, doi: 10.1144/GSL.SP.2003.216.01.15.

Castagna, J. P., and S. Sun, 2006, Comparison of spectral decomposition methods: First Break, v. 24, p. 75-79.

Collot, J.-Y., K. Lewis, G. Lamarche, and S. Lallemand, 2001, The giant Ruatoria debris avalanche on the northern Hikurangi margin, New Zealand: Result of oblique seamount subduction: Journal of Geophysical Research, v. 106, no. B9, p. 19271-19297, doi:10.1029/2001JB900004.

Deptuck, M. E., D. C. Mosher, D. C. Campbell, J. E. HughesClarke, and D. Noseworthy, 2007, Along slope variations in mass failures and relationships to major Plio-Pleistocene morphological elements, Sw Labrador Sea, in V. Lykousis, D. Sakellariou, and J. Locat, eds., Submarine mass movements and their consequences: Dordrecht, the Netherlands, Springer, p. 37-45, doi:10.1007/978-1-4020-6512-5_5.

Dyke, C. G., and L. Dobereiner, 1991, Evaluating the strength and deformability of sandstones: Quarterly Journal of Engineering Geology and Hydrogeology, v. 24, no. 1, p. 123-134, doi:10.1144/GSL.QJEG.1991.024.01.13.

Gamboa, D., T. Alves, and J. Cartwright, 2011, Distribution and characterization of failed (mega)blocks along salt ridges, southeast Brazil: Implications for vertical fluid flow on continental margins: Journal of Geophysical Research, v. 116, no. B8, 20 p., doi:10.1029/2011JB008357.

Gautier, D. L., K. J. Bird, R. R. Charpentier, A. Grantz, D. W. Houseknecht, T. R. Klett, T. E. Moore, et al., 2009, Assessment of undiscovered oil and gas in the Arctic: Science, v. 324, no. 5931, p. 1175-1179, doi:10.1126 /science.1169467.

Goulty, N. R., 2012, Properties of polygonal fault systems - Fluid flow, aligned arrays and simple shear: 74th European Association of Geoscientists \& Engineers Conference and Exhibition Incorporating EUROPEC 2012, Copenhagen, Denmark, June 4-7, 2012, p. 4687-4691, doi:10.3997 /2214-4609.20148867.

Gregersen, U., J. R. Hopper, and P. C. Knutz, 2013, Basin seismic stratigraphy and aspects of prospectivity in the NE Baffin Bay, northwest Greenland: Marine and Petroleum Geology, v. 46, p. 1-18, doi:10.1016/j.marpetgeo.2013.05.013.

Gregersen, U., P. C. Knutz, and J. R. Hopper, 2016, New geophysical and geological mapping of the eastern Baffin Bay region, offshore West Greenland: Geological Survey of Denmark and Greenland Bulletin, v. 35, p. 83-86.

Gregersen, U., P. C. Knutz, H. Nøhr-Hansen, E. Sheldon, and J. R. Hopper, 2019, Tectonostratigraphy and evolution of the West Greenland continental margin: Bulletin of the Geological Society of Denmark, v. 67, p. 1-21.

Hampton, M. A., H. J. Lee, and J. Locat, 1996, Submarine landslides: Reviews of Geophysics, v. 34, no. 1, p. 33-59, doi:10.1029/95RG03287.

Harbitz, C. B., G. Parker, A. Elverhøi, J. G. Marr, D. Mohrig, and P. A. Harff, 2003, Hydroplaning of subaqueous debris flows and glide blocks: Analytical solutions and discussion: Journal of Geophysical Research, v. 108, no. B7, p. 2349-2367, doi:10.1029/2001JB001454.

Henriksen, N., A. K. Higgins, F. Kalsbeek, and T. C. R. Pulvertaft, 2009, Greenland from Archaean to Quaternary. Descriptive text to the 1995 geological map of Greenland, 1:2,500,000: Geological Survey of Denmark and Greenland Bulletin, v. 18, p. 90.

Huvenne, V. A. I., P. F. Crocker, and P. Henriet, 2002, A refreshing 3D view of an ancient sediment collapse and slope failure: Terra Nova, v. 14, p. 33-40.

Jackson, C. A.-L., 2011, Three-dimensional seismic analysis of megaclast deformation within a mass transport deposit; implications for debris flow kinematics: Geology, v. 39, no. 3, p. 203-206, doi:10.1130/G31767.1.

Jakobsson, M., L. Mayer, B. Coakley, J. A. Dowdswell, S. Forbes, B. Fridman, H. Hodnesdal, et al., 2012, The International Bathymetric Chart of the Arctic Ocean (IBCAO) version 3.0: Geophysical Research Letters, v. 39, no. 12, 6 p., doi:10.1029/2012GL052219.

Japsen, P., J. M. Bonow, P. F. Green, J. A. Chalmers, and K. Lidmar-Bergström, 2006, Elevated, passive continental margins: Long-term highs or Neogene uplifts? New evidence from West Greenland: Earth and Planetary Science Letters, v. 248, no. 1-2, p. 330-339, doi: 10.1016/j.epsl.2006.05.036. 
Kehle, R. O., 1970, Analysis of gravity sliding and orogenic translation: Geological Society of America Bulletin, v. 81, p. 1641-1664.

Knutz, P. C., U. G. Gregersen, and J. R. Hopper, 2012, Late Paleogene submarine fans in Baffin Bay and north-west Greenland: 74th European Association of Geoscientists \& Engineers Conference and Exhibition Incorporating EUROPEC 2012, Copenhagen, Denmark, June 4-7, 2012, p. 1799-1803, doi:10.3997/2214-4609.20148203.

Knutz, P. C., J. R. Hopper, U. Gregersen, T. Nielsen, and P. Japsen, 2015, A contourite drift system on the Baffin Bay-West Greenland margin linking Pliocene Arctic warming to poleward ocean circulation: Geology, v. 43, no. 10, p. 907-910, doi:10.1130/G36927.1.

Knutz, P. C., A. M. W. Newton, J. R. Hopper, M. Huuse, U. Gregersen, E. Sheldon, and K. Dybkjær, 2019, Eleven phases of Greenland Ice Sheet shelf-edge advance over the past 2.7 million years: Nature Geoscience, v. 12, no. 5, p. 361-368, doi:10.1038/s41561-019-0340-8.

Kuijpers, A., T. Nielsen, A. Akhmetzhanov, H. de Haas, N. Kenyon, and T. van Weering, 2001, Late Quaternary slope instability on the Faroe margin: Mass flow features and timing of events: Geo-Marine Letters, v. 20, no. 3, p. 149-159, doi:10.1007/s003670000053.

Kvalstad, T. J., L. Andresen, C. F. Forsberg, K. Berg, P. Bryn, and M. Wangen, 2005, The Storegga slide: Evaluation of triggering sources and slide mechanics: Marine and Petroleum Geology, v. 22, p. 245-256.

Larsen, L. M., L. M. Heaman, R. A. Creaser, R. A. Duncan, R. Frei, and M. Hutchinson, 2009, Tectonomagmatic events during stretching and basin formation in the Labrador Sea and the Davis Strait: Evidence from age and composition of Mesozoic to Palaeogene dyke swarms in West Greenland: Journal of the Geological Society, v. 166, no. 6, p. 999-1012, doi:10.1144/0016-76492009-038.

Lee, C., J. A. Nott, and F. B. Keller, 2004, Seismic expression of the Cenozoic mass transport complexes, deepwater Tarfaya-Agadir Basin, offshore Morocco: Offshore Technology Conference, Houston, Texas, May 3-6, 2004, OTC-16741-MS, 18 p., doi:10.4043/16741-MS.

Le Hir, P., F. Cayocca, and B. Waeles, 2011, Dynamics of sand and mud mixtures: A multiprocess-based modelling strategy: Continental Shelf Research, v. 31, no. 10, p. S135-S149, doi:10.1016/j.csr.2010.12.009.

Masson, D. G., N. H. Kenyon, and P. P. E. Weaver, 1996, Slides, debris flows, and turbidity currents, in C. P. Summerhayes, and S. A. Thorpe, eds., Oceanography: An illustrated guide: London, Manson Publishing, p. 136-151.

Meckel, T., 2010, Classifying and characterizing sand-prone submarine mass-transport deposits: AAPG Search and Discovery article 50270, accessed September 1, 2018, http://www.searchanddiscovery.com/pdfz/documents/2010 /50270meckel/ndx_meckel.pdf.html.

Minisini, D., F. Trincardi, A. Asioli, M. Canu, and F. Foglini, 2007, Morphologic variability of exposed mass-transport deposits on the eastern slope of Gela Basin (Sicily channel): Basin Research, v. 19, no. 2, p. 217-240, doi: $10.1111 /$ j.1365-2117.2007.00324.x.
Mohrig, D., C. Ellis, G. Parker, K. X. Whipple, and M. Hondzo, 1998, Hydroplaning of subaqueous debris flows: Geological Society of America Bulletin, v. 110, no. 3, p. 387-394, doi: 10.1130/0016-7606(1998)110<0387:HOSDF>2.3.CO;2.

Morris, W. R., and C. J. Busby-Spera, 1988, Sedimentologic evolution of a submarine canyon in a forearc basin, Upper Cretaceous Rosario Formation, San Carlos, Mexico: AAPG Bulletin, v. 72, no. 6, p. 717-737.

Newton, A. M. W., P. C. Knutz, M. Huuse, P. Gannon, S. H. Brocklehurst, O. R. Clausen, and Y. Gong, 2017, Ice stream reorganization and glacial retreat on the northwest Greenland shelf: Geophysical Research Letters, v. 44, no. 15, p. 7826-7835, doi:10.1002/2017GL073690.

Nissen, S. E., N. L. Haskell, C. T. Steiner, and K. L. Coterill, 1999, Debris flow outrunner blocks, glide tracks, and pressure ridges identified on the Nigerian continental slope using 3-D seismic coherency: Leading Edge, v. 18, no. 5, p. 595-599, doi:10.1190/1.1438343.

Oakey, G. N., 2005, Cenozoic evolution and lithosphere dynamics of the Baffin Bay - Nares Strait region of Arctic Canada and Greenland: Amsterdam, the Netherlands, Netherlands Research Centre for Integrated Solid Earth Science, $233 \mathrm{p}$.

Oakey, G. N., and J. A. Chalmers, 2012, A new model for the Paleogene motion of Greenland relative to North America: Plate reconstructions of the Davis Strait and Nares Strait regions between Canada and Greenland: Journal of Geophysical Research, v. 117, no. B10, 28 p., doi:10.1029/2011JB008942.

Omosanya, K. O., and T. M. Alves, 2013, A 3-dimensional seismic method to assess the provenance of masstransport deposits (MTDs) on salt-rich continental slopes (Espírito Santo Basin, SE Brazil): Marine and Petroleum Geology, v. 44, p. 223-239, doi:10.1016 /j.marpetgeo.2013.02.006.

Planke, S., J. Christensen, S. Polteau, and R. Myklebust, 2009, Mid-Cretaceous source rock subcropping in the Baffin Bay: GEO ExPro, v. 6, no. 1, p. 8.

Posamentier, H. W., 2004, Seismic geomorphology: Imaging elements of depositional systems from shelf to deep basin using 3D seismic data: Implications for exploration and development, in R. J. Davies, J. A. Cartwright, S. A. Stewart, M. Lappin, and J. R. Underhill, eds., 3D seismic technology: Application to the exploration of sedimentary basins: Geological Society, London, Memoirs 2004, v. 29, p. 11-24.

Posamentier, H. W., R. J. Davies, J. A. Cartwright, and L. J. Wood, 2007, Seismic geomorphology - an overview, in R. J. Davies, H. W. Posamentier, L. J. Wood, and J. A. Cartwright, eds., Seismic geomorphology: Applications to hydrocarbon exploration and production: Geological Society, London, Special Publications 2007, v. 277 , p. 1-14.

Prior, D. B., B. D. Bornhold, and M. W. Johns, 1984, Depositional characteristics of a submarine debris flow: Journal of Geology, v. 92, no. 6, p. 707-727, doi:10.1086 1628907.

Raynal, O., F. Bouchette, R. Certain, M. Séranne, L. Dezileau, P. Sabatier, J. Lofi, et al., 2009, Control of alongshore- 
oriented sand spits on the dynamics of a wave-dominated coastal system (Holocene deposits, northern Gulf of Lions, France): Marine Geology, v. 264, no. 3-4, p. 242-257, doi: 10.1016/j.margeo.2009.06.008.

Rider, M., and M. Kennedy, 2011, The geological interpretation of well logs: Cambridge, United Kingdom, Rider-French Consulting, $432 \mathrm{p}$.

Rusconi, F. J., T. A. McGilvery, and C. L. Liner, 2018, Tracks, outrunner blocks, and barrier scours: 3-D seismic interpretation of a mass transport deposit in the deepwater Taranaki Basin of New Zealand (abs.): AAPG Annual Convention and Exhibition 2018, Salt Lake City, Utah, May 20-23, 2018, accessed September 1, 2018, http:// www.searchanddiscovery.com/abstracts/html/2018 /ace2018/abstracts/2836190.html.

Shipp, R. C., P. Weimer, and H. W. Posamentier, 201 1, Masstransport deposits in deepwater settings: An introduction, in R. C. Shipp, P. Weimer, and H. W. Posamentier, eds., Mass transport deposits in deepwater settings: Tulsa, Oklahoma, SEPM Special Publication 96, p. 3-6, doi:10.2110/sepmsp.096.003.

Soutter, E. L., I. A. Kane, and M. Huuse, 2018, Giant submarine landslide triggered by Paleocene mantle plume activity in the North Atlantic: Geology, v. 46, no. 6, p. 511-514, doi:10.1130/G40308.1.

Sun, Q., T. Alves, X. Xie, J. He, W. Li, and X. Ni, 2017, Free gas accumulations in basal shear zones of mass-transport deposits (Pearl River Mouth Basin, South China Sea): An important geohazard on continental slope basins: Marine and Petroleum Geology, v. 81, p. 17-32, doi:10.1016 /j.marpetgeo.2016.12.029.
Swift, D. J. P., 1968, Coastal erosion and transgressive stratigraphy: Journal of Geology, v. 76, no. 4, p. 444-456, doi:10.1086/627342.

Umpleby, D. C., 1979, Geology of the Labrador Shelf: Ottawa, Ontario, Canada, Department of Energy, Mines and Resources Canada, 41 p., doi:10.4095/105927.

Weimer, P., and C. Shipp, 2004, Mass transport complex: Musing on past uses and suggestions for future directions: Offshore Technology Conference, Houston, Texas, May 3-6, 2004, OTC-16752-MS, 10 p.

Welford, J. K., A. L. Peace, M. Geng, S. A. Dehler, and K. Dickie, 2018, Crustal structure of Baffin Bay from constrained three-dimensional gravity inversion and deformable plate tectonic models: Geophysical Journal International, v. 214, p. 1281-1300, doi:10.1093/gji /ggy 193 .

Whittaker, R. C., N. E. Hamann, and T. C. R. Pulvertaft, 1997, A new frontier province offshore northwest Greenland: Structure, basin development, and petroleum potential of the Melville Bay Area: AAPG Bulletin, v. 81, no. 6, p. 978-998.

Wright, K. A., R. Nice, M. Tazzi, K. Purnell, and V. Penasse, 2018, Spectral decomposition: An aid in characterizing field architectures of the Laggan and Tormore fields, Faroe-Shetland Basin, in M. Bowman and B. Levell, eds., Petroleum geology of NW Europe: 50 years of learning Proceedings of the 8th Petroleum Geology Conference: Geological Society, London, Petroleum Geology Conference Series 2018, v. 8, p. 525-535. 